AperTO - Archivio Istituzionale Open Access dell'Università di Torino

\title{
Multimedia tool suite for the visualization of drama heritage metadata
}

\section{This is the author's manuscript}

Original Citation:

Availability:

This version is available http://hdl.handle.net/2318/148462

since 2016-11-27T19:28:10Z

Published version:

DOI:10.1007/s11042-014-2066-3

Terms of use:

Open Access

Anyone can freely access the full text of works made available as "Open Access". Works made available under a Creative Commons license can be used according to the terms and conditions of said license. Use of all other works requires consent of the right holder (author or publisher) if not exempted from copyright protection by the applicable law. 
This is the author's final version of the contribution published as:

Vincenzo Lombardo;Antonio Pizzo. Multimedia tool suite for the visualization of drama heritage metadata. MULTIMEDIA TOOLS AND

APPLICATIONS. 75 (7) pp: 3901-3932.

DOI: $10.1007 / \mathrm{s} 11042-014-2066-3$

The publisher's version is available at:

http://link.springer.com/content/pdf/10.1007/s11042-014-2066-3

When citing, please refer to the published version.

Link to this full text:

http://hdl.handle.net/2318/148462 


\title{
Multimedia tool suite for the visualization of drama heritage metadata
}

\author{
Vincenzo Lombardo • Antonio Pizzo
}

Received: 26 November 2013 / Revised: 27 March 2014 / Accepted: 29 April 2014

(C) Springer Science+Business Media New York 2014

\begin{abstract}
This paper presents a multimedia tool suite for, on the one hand, the annotation of metadata that encode the dramatic qualities of cultural heritage items, and, on the other, the visualization of such metadata for drama analysis and didactics. The tool suite relies upon an ontology of drama to devise an annotation schema for the metadata concerning the dramatic qualities. The two major modules of the tool suite are a web-based platform, that allows for the insertion of the annotation metadata, and a visualization program for the interactive exploration of such metadata, respectively. The tool suite was tested on the cross-media studies of drama analysis and teaching of drama structure through the application to classical examples.
\end{abstract}

Keywords Drama ontology $\cdot$ Interactive visualization $\cdot$ Metadata annotation

\section{Introduction}

In recent years, Cultural Heritage institutions have been showing interest towards the digital items and the exploitation of the World Wide Web to disseminate the cultural assets to the public [1]. Philological researches on literary texts, as well as on artworks and historical sites, are developing interest toward their own encoding in a digital edition. Besides the well established Text Encoding Initiative $^{1}$ and the semantic annotation, such as as Open Annotation or Europeana data models, ${ }^{2}$ for the insertion of metadata to texts, there are projects that aim at annotating different kinds of heritage, such as Maphub (for the annotation of ancient maps), ${ }^{3}$ GAP (Google Ancient Places), ${ }^{4}$ and PELAGIOS (Pelagios: Enable Linked Ancient Geodata In Open Systems) ${ }^{5}$ for the annotation and visualization of sites related to Latin literature.

\footnotetext{
${ }^{1}$ http://www.tei-c.org/

${ }^{2} \mathrm{http}: / /$ www.europeana.eu/

${ }^{3}$ http://maphub.github.io/api/

${ }^{4} \mathrm{http}: / /$ googleancientplaces.wordpress.com/about/

5http://pelagios-project.blogspot.it/p/about-pelagios.html
}

V. Lombardo $(\bowtie) \cdot$ A. Pizzo

CIRMA and Dipartimento di Informatica, Università di Torino, corso Svizzera 185, Torino, Italy e-mail: vincenzo@di.unito.it

\section{A. Pizzo}

e-mail: antonio.pizzo@unito.it 
However, while heritage artifacts are more and more digitized, there is a general agreement that resources for "cataloguing" the collections and "make them accessible to the tradition bearers and the general public" are lacking [34]; the amount of metadata is very restricted, items come with very short descriptions and scarce contextual information. This also applies to the intangible heritage, that has been recently extending the resource-based tangible heritage to heritage that is "not closely linked to the physical consistency" [63]. Quite often the focus has been on cataloguing the texts and/or the audiovisual resources. Therefore the safeguarding activity has been coinciding with the preservation of the physical storage of the data, in both analogical and digital formats.

This paper addresses the representation and preservation of drama, the intangible heritage that lies beneath those works that tell a story through characters who perform live actions. In its wider meaning, this kind of heritage can incorporate the Greek tragedies, Ibsen's theatrical works, and the most recent Hollywood movie. These resources constitute a large body of evidence for drama studies, and have been increasingly relevant since the availability of digital media. For researchers, digital media can be both the direct object of study (in the case of, e.g., a movie) and the video documentation of theatre performances; they have foreseen a collaborative environment for the creation/sharing/dissemination of the metadata that express knowledge on the essential elements of drama and theatre [15]. We can acknowledge this heritage under the generic term "dramatic media" [22], spanning drama over multiple media. Complying with the UNESCO Convention for the Safeguarding of Intangible Cultural Heritage, in this paper we address the "cultural" side of the dramatic media, pointing to the social and symbolic values [56]. In particular, we employ the notion of story in working on the metadata annotation of dramatic heritage items. So, the dramatic items are those shapes that a story can assume, fulfilling a number of its core conditions. For example, the story abstracted from the oral tale Cinderella has numerous shapes, such as, e.g., Perrault's and Disney's versions.

Here, we propose a multimedia system for the annotation and the visualization of the metadata of the dramatic heritage, with particular attention to audiovisual items; metadata are driven by a model of drama that is encoded in a computational ontology. In the next section, we provide the background of drama heritage and the major features of storytelling and drama, the so-called dramatic qualities, and then, we review the related work on the systems for the annotation and visualization of the drama features. The third section contains an overview of the ontology Drammar, that encodes the dramatic qualities in a machine-readable format and provides the structure for the annotation schema that is implemented in the multimedia system; in particular, the annotation schema allows for the encoding of the incidents occurring in the story world and the characters' motivations in support of those actions. The machine-readable format of the ontology and the annotation allows for the implementation of a web-based interface and of automatic reasoning procedures within the CADMOS multimedia tool suite, that is described in the fourth section. The annotation of the story incidents and the reasoning about the goals and plans allows for the characterization of the motivations underlying characters' behaviors; this augmented knowledge, which merges occurring incidents and supporting motivations, is visualized by the multimedia tool suite. Finally, we provide a validation of the effectiveness of the multimedia tool suite for drama studies and teaching of drama heritage. Conclusions end the paper.

\subsection{Background on drama heritage}

Storytelling is a pervasive activity across all cultures and ages, especially in its dramatic form [40]. In western culture, storytelling has taken many different forms, from fairytales to TV 
fiction, surviving the transformations occurred to media. The importance of storytelling has been acknowledged by studies in all the disciplinary fields, ranging from literary criticism [27] and semiotics [51], to aesthetics [14] and psychology [11]. Within storytelling, drama has grown through different media [22] and is most pervasive from theatre, to cinema, Tv and videogames.

Drama presents a bunch of specific features, that can be defined more or less precisely.

These features refer to identifiable elements in Shakespeare's Romeo and Juliet as well as in Tom Stoppard's Rosencrantz and Guildenstern Are Dead, in the HBO's Sopranos and even in some reality show, such as CBS's Survivors, and, finally, in some famous videogame such as Rockstar Games' L.A. Noir or Ubisoft's Assassin Creeds' series.

The fruition of drama mostly focuses on enjoying the story rather than appreciating the aesthetic features, although the latter are appraised by professionals and knowledgeable users. In fact, it is well known that in dramatic media the audience is engaged by the character's behavior rather than by the literary values. Almost all the repositories of drama and movies hold a synopsis of the story for each of the listed items (see, e.g., the Internet Movie Data Base $^{6}$ ). The notion of "story" is widely acknowledged as the construction of an incident sequence [8], that, abstracting from the cinematographic properties, is motivated by the causeeffect chain [52]; this chain results from a complex interplay among agents, events, and environments, well known in playwriting techniques [19]. Elam names the notion of story as fabula, an abstraction of the sujzet/plot ([20], p. 120); Pfister concludes that "a number of different dramatic texts can be based on one and the same story and also that the same story may even be presented as texts in different media ([48], p. 197)." All these variety of texts and shapes are defined by Ryan as the avatars of story ([53], p. xviii).

Within this framework, drama scholars have developed a number of approaches to dramatic texts and theatrical plays [13]. Given the playwriting techniques mentioned above, here we adopt a so-called constructivist approach, which departs from the linguistic and literal forms to focus on the constitutive elements of drama. So, to explore the common story-based features that reconcile Romeo and Juliet and Assassin Creeds, we focus on features as: how the plot develops and is structurally organized, how characters are involved in the actions, what conflicts take place. In particular, the analyses of Lavandier [35], Ryngaert [54], Hatcher [30], and Spencer [58] distill the dramatic elements that the author has to handle in order to produce a well formed play, relying on the well known vocabulary of dramatic elements, e.g. character, plot, action, deliberation, emotion, conflict.

The Greek origin of the word drama are related to the notion of do, act, performing. Nowadays drama can be seen as a sequence of structured action described in a text or in a score. Szondi has defined the drama as the action at the present time acted directly by characters ([61], pp 194-196). Nevertheless, this does not mean that the drama is the event enacted in front of the audience. As stated by Aristotle, a text, to be dramatic, does not need to be performed ([4], 1453b 1-10) ([3], p. xxxviii). Therefore, we can say that drama is dramatic not because it is presented in front of an audience, but because of its specific tools of mimesis, hence its specific language of actions. Scholars have clearly stated that drama is made of characters' behaviors [10], and that a "dramatic action is not doing something" but "what a character wants" ([58], p. 38). The action has to spread out of the character's inner motivation and must provide clues about its personality and intentions; most importantly, it must produce the high levels of conflicts and the consequent emotional appraisal. Action, intention, conflict are key terms in a computational perspective, because they link the drama to the design of behaviors. We can list the following dramatic elements that are commonly found in drama

\footnotetext{
${ }^{6}$ http://www.imdb.com/
} 
critics. We take as a running example Shakespeare's drama Hamlet, also considering the tangible heritage item of the film directed by Laurence Olivier (Two Cities Film production, UK, 1948). In particular, we address the so-called "nunnery" scene in the Third Act, where Ophelia is sent to Hamlet by Polonius (her father) and Claudius (Hamlet's uncle, the current king) to confirm the assumption that Hamlet's madness is caused by his rejected love. According to the two conspirers, Ophelia should induce him to talk about his inner feelings. At the same time, Hamlet tries to convince Ophelia that the court is corrupted and she should go to a nunnery. In the middle of the scene Hamlet puts Ophelia on a test to verify her honesty (it is the so-called climax of the scene). Because he guesses (correctly) that the two conspirers are hidden behind the curtain, he asks the girl to reveal where her father Polonius is. She decides to lie and replies that he is at home. As a consequence, Hamlet becomes very angry in realizing that even Ophelia is corrupted and there is no hope to redeem the court.

\section{Action}

Drama is a specific manner of organizing actions. This means that the action must have some qualities. The Thirty Six Dramatic Situations represents a seminal point because, from a large repository of plays, it extracts a list of situations that are perceived as dramatic [50]. Each situation is a specific action (e.g. Vengeance). Within each situation, and its subdivisions, Polti defines: the kind of agents described (e.g. assassin, victim); the relations among agents (e.g. affinity, love, kinship, etc.); beliefs and goals that motivate the action (e.g. the agent's planning); the effects on the world; and the action's emotional charge. For example, Ophelia's action of lying about her father's location is motivated by her goal of respecting Polonius' authority and the belief that Polonius is behind the curtain.

\section{Agent}

Action involves at least one agent and must be the outcome of a deliberative process ([3], p. xxiv). Hence the action must involve agents with goals, deliberations and emotional states. Modern drama has overcome the notion of the character as a whole nucleus (e.g. the romantic hero), and has developed the idea of a character consisting of the sum of its actions [54]. Therefore, the agent is a willing dynamic entity that constantly appraises the state of its world by means of rational deliberation and emotional charge. For example, the "nunnery" scene is carried out by two agents who interact according their own beliefs and feelings.

\section{Conflict}

Not all the actions carried by an agent are dramatic. This quality spreads from a tension or an opposition among the agents, or between the agent and the environment. The notion is ubiquitous in drama critics.

Leaving aside the opposition between the tragic hero and the fate in classical Greek plays, we can easily trace it back to 1758 with the seminal work of Diderot, who foresees a conflict based on the opposition between the character and the social environment [18]. Years later, Lessing also wrote about an opposition driven by character's different moral values, therefore motivated by the inner feeling [36]. For Hegel's Aesthetics, the notion of conflict is at the core of the drama: drama is not a mere representation of an enterprise which peacefully runs its 
course. It has interest only from the animated strife between its personages and their struggle and perils. It gives us the final result of these conflicts ([32], p. 287). His whole perspective on drama is based upon the conflict as a core element that drives the character's creation and the storyline. From here onward, conflict became unmissable in the literature and was addressed in more detail. On the one side, it has been seen as the main engine of the plot because it provides reasons to characters' change [19]; on the other side, it has been divided in types (e.g., inner, interpersonal, social [41]). Nevertheless, the main contribution on conflict is to represent the obstacle in a notion of drama as the struggle of an agent toward her/his desires [35].

The action in the "nunnery" scene is dramatic because of the two characters' conflicting goals: Hamlet wants to turn Ophelia away from the court's influence; her wants to respect Polonius' authority.

\section{Dramatic Arc}

The agent's actions in conflict must be organized to give a sense of causality and wholeness, i.e. in a plot. In other words, the single action is not only dramatic (as described by Polti's situations), but must be part of a sequence of actions that are ordered. The order is driven by the raising tension and is normally described as an arc along the temporal line. Therefore the sequence must be constructed according to a well established pace that goes from the introduction, to rising, climax and return [25].

In the "nunnery" scene, Hamlet quietly starts by trying to convince Ophelia to go to a nunnery (to escape the corrupted of Elsinor), proceeds rising his tension to test Ophelia about her honesty, reaches a tension top after realizing that even Ophelia is corrupted, and turns his attention away from his love for Ophelia to his father's revenge as a result.

\section{Units}

The wholeness of drama springs from its parts. Although it is usual to describe drama in terms of acts and scene (or sequence for a movie), from Freytag onward it is clear that the subdivision of plot does not respond to practical reasons (such as characters' entrances or exits) but to dramatic reason. In other words, the actions must be grouped according to their goal, conflicts and solutions; and each group can be furtherly grouped as well, leading to the macro segmentation in three or five acts [35] [23]. These grouped actions are narrative blocks that may be seen as units that compose the dramatic arc. The units are the containers of the character's actions and may be graded according the quality of obstacles, conflicts, and changes that take place in it [48]. Although the notion of unit is ubiquitous in drama critics, there is no shared opinion about the rules that define its boundaries. Beside the traditional narrative segmentation that follow the development of the story timeline [58], there are more complex approaches that link directly the unit to the character's value at stake [41].

In the "nunnery" scene, the changing goals of Hamlet, with the corresponding tension rising described above, mark the succession of a number of units, each carrying out a number of actions that implement Hamlet's appeal to Ophelia to go to a nunnery, testing of Ophelia honesty, reaction to his angriness about Ophelia corruption, his leaving Ophelia to face her own fate. 


\section{Emotion}

Whatever point of view we adopt to define the units and their sequencing in the dramatic arc, it is clear that all is driven by conflict and the result has to lead to some emotional charge. Therefore the units can be described also as emotional episodes ([55], p. 39), in which the agent feels some emotion as a result of his appraisal of the situation. Emotions represent the crucial aspect of the design of a dramatic action, because they are the glue of the elements of drama listed above (actions, conflict, and dramatic arc), that are all qualified by the emotion represented (e.g., the climax shows an action that spills out from -or causes- a strong and deep emotion, while the introduction can contain more descriptive events). But they are also crucial because they allow the audience to fully appraise the action and its meaning in the plot. A character charged with the right emotion will secure the emotional bonding with the audience.

In the "nunnery" scene, Hamlet, as a consequence of his and Ophelia's actions, feels Distress, for discovering that his belief that Ophelia is honest is false, and Anger, after Ophelia's lie about her father.

In this paper, we adopt a formal encoding of the dramatic elements through the Drammar ontology [38]. The goal of this paper is to provide a multimedia system (actually, a toolsuite) for the annotation of such elements and their visualization, in order to provide scholars and enthusiasts with a tool that supports drama analysis and didactics.

\section{Related work}

This section surveys the multimedia systems for the annotation of metadata for drama and for the visualization of dramatic qualities, respectively. We address both specific systems and multimedia tools that contribute to our work.

The problem of metadata annotation for cultural heritage has received some attention recently. Some authors have resorted to Wikipedia, which offers in-depth descriptions and links to related articles, and is thus a natural target for the automatic enrichment of heritage items (see, e.g., [2]). In the field of video indexing in general (not necessarily of drama genre), semantic descriptors are automatically associated with videos and individual concepts, organized in an ontology, are connected through the creation of semantic relations. For example, LSCOM is an ontology of concepts targetedly designed for a corpus of broadcast news [43] and the MediaMill dataset relies on a set of 101 semantic descriptors that are best suited for that repository [57]. In the specific domain of the performing arts (which are related to drama), the tool MyStoryPlayer is a specifically designed interface for the semantic annotation of documents (such as video, audio, text, image, ..., encoded in RDF format) and the navigation of the annotations creating its own non-linear experience or path [7].

In the domain of annotation for drama specifically, there exist approaches that guide the annotation for the formal encoding of the story elements. The Story Intention Graph [21] relies on the representation of the short-term characters' intentions to build an interpretive layer of a narrative text; the Stories ontology, ${ }^{7}$ developed in collaboration with the BBC for the application in news, the storylines of Doctor Who episodes, and historical facts, is an event-(instead of character-) based description of the timeline of story incidents, with no interpretive intents.

\footnotetext{
${ }^{7}$ http://www.contextus.net/stories
} 
Finally, one can rely on user-generated metadata, such as the tags that are freely inserted by users to annotate the items contained in public repositories. [37] report an informal survey carried out on the clips extracted from the feature film North by Northwest (the famous 1959 MGM-Hitchcock's movie), contained in the YouTube repository. The survey reveals that of the 183 unique tags, split manually, into eleven different categories (Title, Actor, Director, Production, Editing, Publish, Genre, Character, Object, Environment, Action), following grounded-theory based analysis [59], only 32 could be interpreted as content metadata (such as, e.g., auction, boulevard), with most tags referring to characters ("Roger", "mother") or their qualities ("blonde", "dress"). The other tags all concern the resource itself (actors, director, ...) and could be retrieved from other sources, such as IMDB.

Nevertheless, none of these systems has yet developed a consistent and comprehensive metadata system, based on a shared set of constructs, that can appropriately reflect the aforementioned vocabulary of dramatic elements.

The visualization of the relations holding over the drama elements has been addressed by visual artists and designers to provide unique maps for orientation, especially in dramas that are difficult to grasp on behalf of the audience. Two well known cases are Nolan's films Memento $^{8}$ (director Christopher Nolan, 2000) and Inception ${ }^{9}$ (director Christopher Nolan, 2010). On a more productive side, a number of visual interfaces come with software tools that have been developed to assist the creation and production of dramas, providing editors for formatting, segmenting and cross-referring the several parts of a drama, including the management of the basic participants, namely characters, environments, locations, objects. ${ }^{10}$ The writing assistant Dramatica Pro ${ }^{11}$ visualizes the building blocks of a plot structure, with diagrams for plot progression and story points, that help the writer in controlling and balancing the tension within the story development. However, the connections fleshed out are useful to connect the several professionals of the production and not to the visualization and exploration of the dramatic qualities that link intentions to actions (actually because the writing practice does not have a formal representation of goals and plans beside the well established, yet narrative form of the character's lines).

More in general, there exist a variety of areas of creativity that concern events unfolding over time and occurring in some space. All these areas usually benefit from a narrative mapping, i.e. a visualization of the events through a combination of "information graphics, journalistic diagramming, visualizations, reconstructions, and some conventional-looking (but ambitious) geographic maps" [39]. The aim is towards a representation of the event structure, with the possibility of carrying out analyses for specific aspects of the narrative. The result is the creation of an information space where the bits and pieces of some endeavor find an appropriate place in some structure and the design of novel interfaces for the exploration of such a space. For example, Narratives [24] is a system for viewing temporally-changing data based on keyword visualization, working with a corpus of blog entries that talk about news stories. The visualization relies upon a line graph, with users that can interact to see what additional concepts are most associated with a selected term. Going closer to the drama topic of concern here, Narrative theatre [5] is a tool for supporting the creation of fables. It relies on a computational framework that leverages the knowledge about the writing domain in order to reason about the events and create a visual representation of each event. It mostly focus on the creation of storyboards from the written text.

\footnotetext{
${ }^{8} \mathrm{http} / / /$ visual.ly/memento-scene-timeline

${ }^{9} \mathrm{http}: / /$ visual.ly/inception-timeline-visualisation

${ }^{10}$ See, e.g., the commercial products Final Draft, Movie Magic, Celtix, Script It!

${ }^{11} \mathrm{http} / /$ www.writersstore.com/dramatica-pro-story-development-software/
} 
Tree layout, especially in the case of multiple trees spanning the same set of basic elements (usually the leaves of a tree) has been the object of several approaches of information visualization (see the survey in [28] on single and multiple trees). Node-link, nested squares or circles, horizontal and vertical adjacency, indented-list, and matrix representations are well known in the literature, each with specific advantages and disadvantages, depending on the task at hand.

Some work [12] has also addressed the problem of stitching together hierarchical structure and time into one visualization space, in order to help an analyst understand how very large hierarchies change through time; the goal is to enable the analyst to detect patterns of relationships. In our case, the interest is in the visualization of multiple trees that span the same frontier (provided by the timeline of story incidents). In particular, here we refer to the timeline of incidents that occur in a narrative plot (leaf nodes of a tree), that result from the projection of the characters' plans (internal nodes). Since, the several characters' intentions are hierarchically organized into overlapping trees, the necessity of multiple tree visualization arises.

\section{Ontology representation of story metadata}

In this section, we introduce the ontology Drammar, while keeping as a running example the drama Hamlet.

Drammar is a computational ontology, ${ }^{12}$ encoded in the OWL language. Drammar is designed with the twofold goal of providing a formalized conceptual model of the dramatic elements as described in section 2 and an annotation schema for the insertion of the metadata of a dramatic item.

In Fig. 1, there is the top level of the Drammar ontology. Each class has then a number of subclasses; we will describe the most relevant here; a complete description is in [16].

A unit (Unit class, left of Thing in the Fig. 1) is based on the notion of Unit as dramatic element. It is a chunk of the story, identified by the annotator according to actional boundaries, i.e. it is characterized by the occurrence of some incidents, of which we can recognize beginning and end. It empirically occurs that a DramaUnit is a unit displaying a conflict (also see below for the representation in Drammar): in this case, the incidents of the unit are motivated by a conflict between characters that plays a key role as dramatic element (see conflict mentioned in section 2). The units that do not have conflicts but participate to the construction of a dramatic unit are defined as actional (consider, e.g., the initial units of a story where the major characters are introduced through incidents of their everyday lives). For example, the unit we describe in Fig. 3 includes two incidents: the request of Hamlet who asks a question to Ophelia about Polonius' location ("Where is your father?") and the reply of Ophelia who tells that Polonius is at home ("At home, my lord"). ${ }^{13}$ Drammar complements the notion of unit with the notion of StoryState: a story state is a set of states (the State is a subclass of the class Dynamics, see below) that hold between two units. So, for example, a state that holds before the unit occurs is that Hamlet believes that Polonius is in the room (this

\footnotetext{
${ }^{12}$ See [29] for an introduction to computational ontologies.

${ }^{13}$ This example is also interesting to point out that the decision to annotate a fragment of drama hinges on the interpretation of the annotator. Other dialogues, even in a shakespearian drama, are annotated as a single incident; but in this case, that is the climax of scene, the two incidents result from a complex decision making process of the two characters and so the annotator decided to keep them apart, though, as we see below, they are connected through the two goals in conflict.
} 


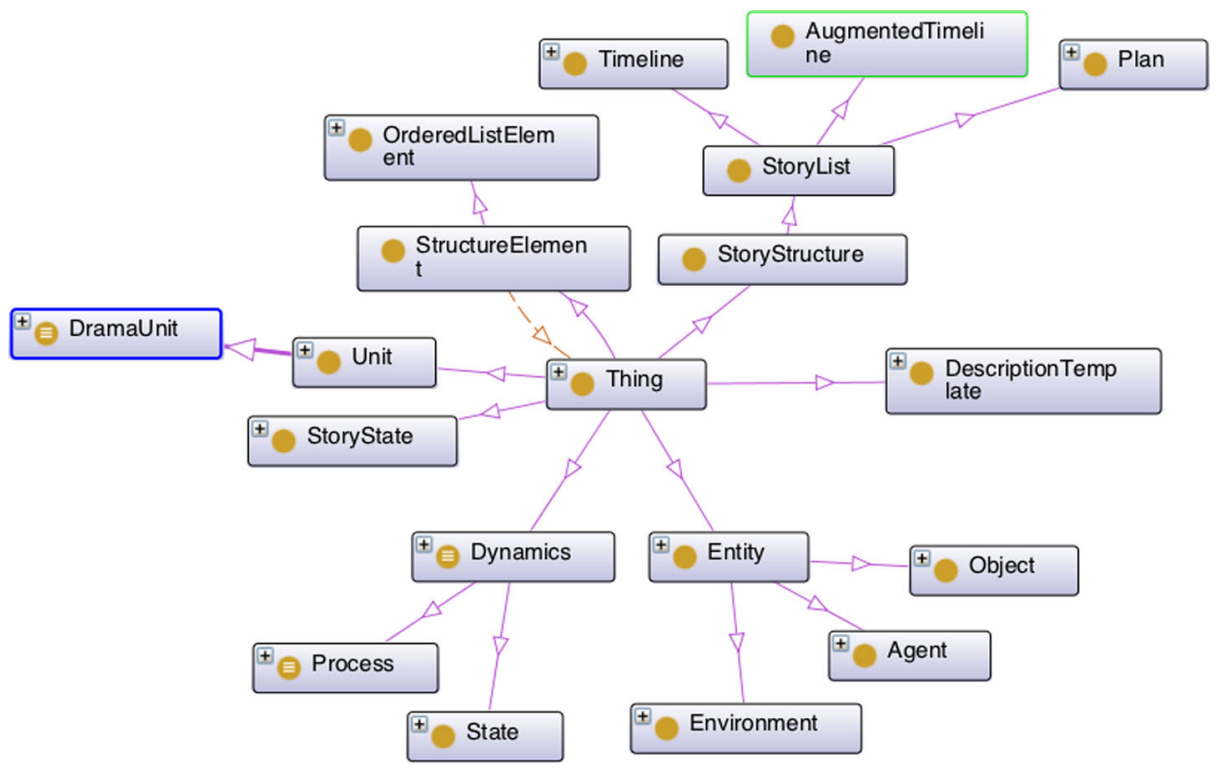

Fig. 1 Top level classes of the Drammar ontology

is a precondition for the rhetorical question), while a state that holds after the unit is that Hamlet does not believe that Ophelia is honest.

The class Entity (lower part of Fig. 1) models all the story elements participating in the unit, namely Agent (the elements who are characters that intentionally act in the incidents and may be referred to the Agent element in section 2), Object (the elements that do not own intentions), and Environment (the locations where the incidents take place).

All the entities feature qualities (e.g. speed or color), status (e.g., open/closed), a type (e.g., an individual telephone Object in a scene belongs to the class of the telephones), a message conveyed by an object (e.g., a billboard with the name of a toothpaste brand). In general, following the paradigm of linked data [31], all the qualities are represented as URI's referring to some external commonsense or specific ontology. All such references are realized through the class ExternalReference (Fig. 2). Each entity (as well as a Dynamics, see below) connects to its qualities through an individual of the class ExternalReference (or of its subclasses), that then connects to some external URI. For example, in Fig. 2, we see on the right some "ExternalReference" individuals for the entities in the unit above: the object types of "father", "room", "prince", and "girlfriend", and the value "Honesty". Drammar refers to two external large-scale semantic resources for the description of the commonsense knowledge, namely the two ontologies Suggested Upper Merged Ontology (SUMO, [46]) and Yet Another Great Ontology (YAGO [60]), merged into YAGO-SUMO [17], which provide very detailed information about millions of situations, including entities (agents and objects), processes/ actions, and events (see below, Dynamics, for processes and events). Terms in YAGO-SUMO are accessed through a lexical resource, the WordNet lexical data base [42 $]^{14}$; in particular, the multimedia system realizes an interface for supporting the manual selection of concepts, extending the vocabulary to a multilingual setting (through the lexical data base MultiWordNet [49]), to increase the interoperability of the annotation data across languages.

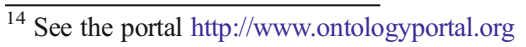




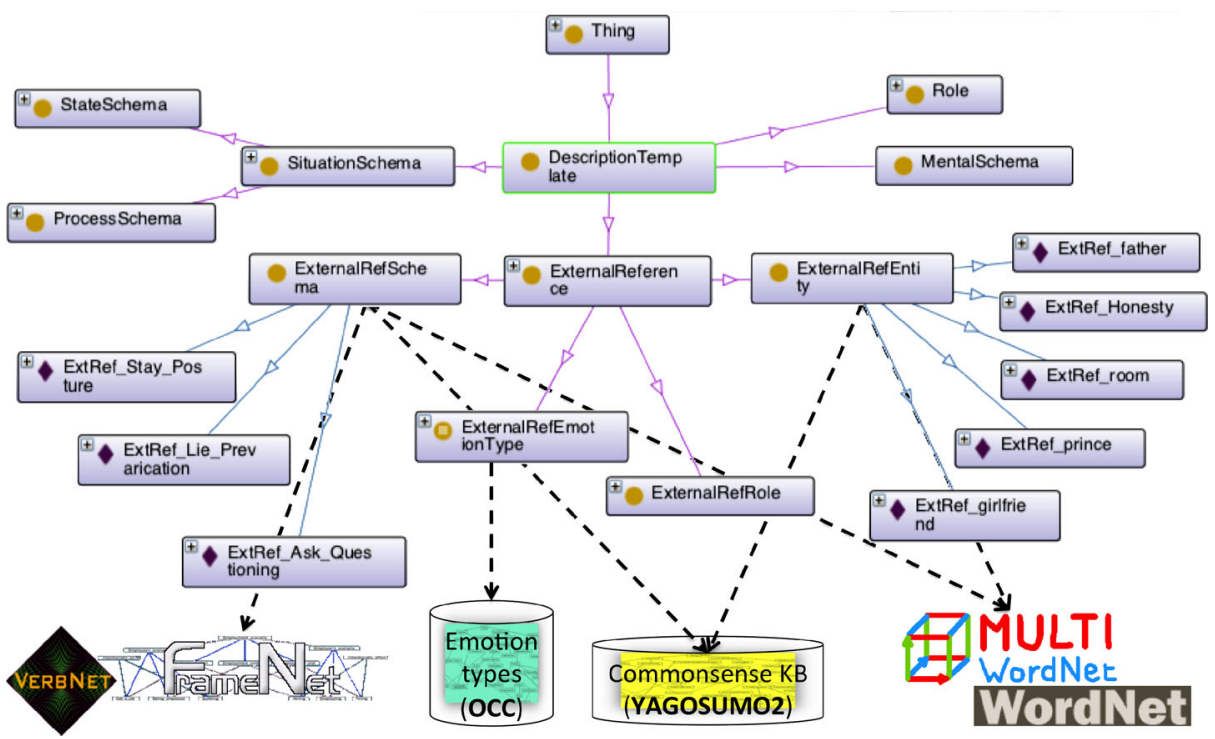

Fig. 2 The connection between the ontological elements of Drammar and the external resources through the individuals of the QualeClass. In particular, Entities are connected to YAGOSUMO through the Wordnet-based resources; Process Schemata are connected to YAGOSUMO through Wordnet and Framenet resources

In some particular cases, some features refer to some specific data (e.g., the string "Where is your father?" represents the message conveyed by Hamlet's utterance to test Ophelia's honesty).

The class Dynamics (lower left of Fig. 1) provides the elements for the story dynamics, namely processes and states, represented by the subclasses Process and State, respectively. Processes are the abstractions of the actual incidents that occur in a unit and are based onto the Action element in section 2). Incidents, which are the processes instantiated for a specific unit, can be intentional or unintentional (the latter occur without an agent commitment). States are related to Processes in that they hold as preconditions of some processes, i.e. they must hold before a process can occur, or effects of process, i.e. they hold after the occurrence of a process. States are used to describe the motivations for the Plans of the Agents, who formulate and aim at achieving some Goal as a result of their Values put at stake and their Believes.

The representation of processes and states (see Fig. 3) is driven by the Time Indexed Situation design pattern developed in the descriptive ontology DOLCE [26]. The idea of adopting patterns from external, well known ontologies, is useful for the sake of interoperability. Entities participate in processes and states according to some Role, that is defined by a SituationSchema (split into ProcessSchema and StateSchema). All processes and states are described by (property isDescribedBy) a situation schema. All the schemata belong to the class DescriptionTemplate, which provide the templates for a number of ontological structures, sometimes referring to a pattern (see a detailed example below). Templates are described by the frames of Framenet [6] (see Fig. 2), which depict situations, processes/actions, and/or events in terms of roles played by the elements that participate in it; in case some linguistic term has no corresponding frame in Framenet, we resort to the generic thematic roles (such as, e.g., "Agent" and "Recipient" for Hamlet and Ophelia, respectively, in the action "Hamlet shouts out at Ophelia") of the verb lexicon Verbnet [33]. 


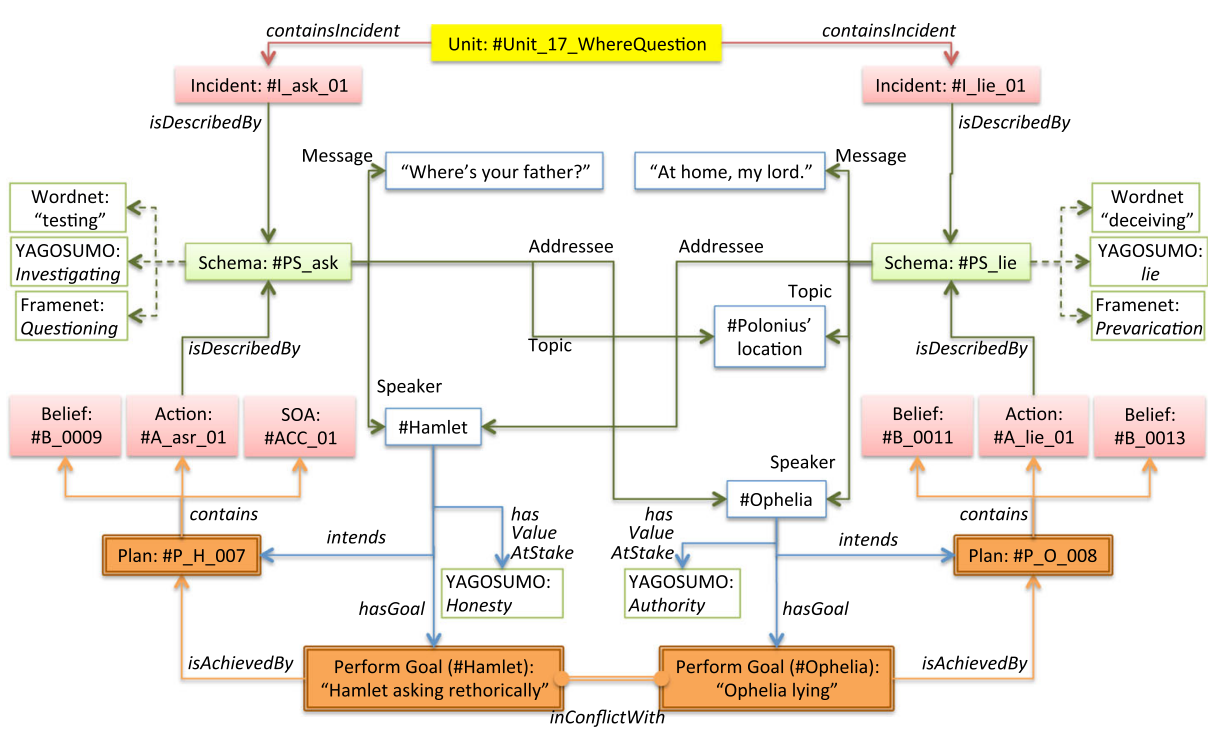

Fig. 3 The annotation of the Unit \#Unit1 where the Agent \#Hamlet tests (concept \#Investigating, frame \#Questioning) the Agent \#Ophelia's honesty by asking about Polonius' location and she lies (concept \#lie, frame \#Prevarication) about it. The structure is built upon relations on roles and role fillers. Testing and lying are the two processes that describe the two incidents, respectively. Notice the conflict between the Hamlet's and Ophelia's goals, respectively

The class State is broken up into two subclasses: StateOfAffairs, i.e. states that hold in the story world, and MentalState, i.e. states that are claimed to hold within the mind of one Agent. Mental states are at the core of the intentional behavior of agents. Agents, in fact, are the most complex entities (such a complexity is revealed by the number of properties having agents as domain). Agent representation in Drammar descends from the BDI theory [9], which has already seen some applications in the computational storytelling community [44] [47]. According to BDI, an agent is a tripartite function of Beliefs, Desires (or Goals), and Intentions (or Plans of actions), where beliefs are the knowledge of the agent (what it knows or believes to be true), goals are the objectives to be achieved through the plans of actions. Beliefs and Goals are states; Plans are actions surrounded by precondition and effect states; plans are hierarchically organized in subplans, until base plans that provide a context to individual actions (see below). Beyond Beliefs and Goals, Drammar includes agents' Emotions and Values, who are credited to be relevant in characterizing drama in terms of emotional appraisal as in section 2. While Values can refer to any term in the YAGO-SUMO ontology, Emotions refer to the emotion types classified by [45]: they build a tripartite ontology, according to what triggers the emotion to a character (events occurring in the world, actions carried out by the same character or another one, and pleasantness of an object, respectively), and then refine the classification through desirability/blameworthiness of the trigger (e.g., "Hope"), or if it has occurred in the past or is to occur in the future (e.g., "Satisfaction").

The agent's mental states concern one of the following classes:

- Belief: the agent's subjective view of the world (e.g., Hamlet believes "Ophelia is not loyal");

- Emotion: what the agent feels (e.g., Hamlet is in "Love" with Ophelia); 
- Value: the moral qualities of an agent, that are put at stake along the narrated story (e.g., Hamlet's value put at stake is Honesty);

- Goal: objectives that motivate the actions of the agents; in accordance with agent theories, Drammar acknowledges different goal types (cf. [62]), depending upon their propositional content: perform goal (PG), that aims at the execution of a certain action; achievement goal (AG), that aims at the achievement of a certain state of the world; query goal (QG), a type of achievement goal, where the state to be achieved is a belief state of the agent itself; maintenance goal (MG), that aims at keeping or restoring a certain state in the story world.

Beliefs and goals are PropositionalAttitude of the agent (property owns) towards some incident or state (specified through the property propositionalContent).

Given the classes so far stated, the Hamlet "nunnery scene" can be summarized as follow: Ophelia (Agent) is going to meet Hamlet (Agent) because she wants (Goal) that he reveals his inner feelings. When he arrives, she tries to returns (ActionInUnit) some love gifts (ObjectInUnit). In the scene, Ophelia feels a distress (Emotion) because the authority (Value) of her father is at stake. Hamlet refuses the gift and denies he ever gave her anything.

The classes StoryStructure and StructureElement model how units are put together in a Timeline (the story evolution) and actions and states are put together to form a Plan (the latter are hierarchically organized). This classes respond to the needs of ordered sequence in drama as defined by the Dramatic Arc notion in section 2.

So far, the only StoryStructure we have in Drammar is the StoryList (see top of Fig. 1). StoryList features three types of sequences: the Timeline is the sequence of units (and, in turn, of incidents) forming the story; the Plan is the sequence of actions or subplans, with precondition and effect states at the two extremes, through which a character intends to achieve a goal (connected through the property obtainedThrough); the AugmentedTimeline is the Timeline, with units interspersed with states that hold for each pair of units. Base plans are made of one action; recursive plans are made of subplans to represent long-term intentions; subplans eventually are mapped onto base plans (see the group and subgroup notion in Unit element in section 2). So, the timeline is the actual story development and the plans represent the cognitive deliberations of the agents that motivate that development.

The plans that are motivating the actions of the example unit above exhibit the following hierarchical structure: the medium term goal of Hamlet is the query goal of learning about Ophelia's honesty, which is then developed as two subplans in which Hamlet asks Ophelia a rhetorical question about Polonius' location (so, Hamlet's Perform Goal of asking a rhetorical question) and Ophelia tells the truth (Perform Goal of telling that Polonius is in the room, what Hamlet already knows). The first subplan is implemented as the following base plan:

Base plan: \#P_H_007 (Hamlet) [PG: Hamlet asking rhetorically Ophelia about Polonius' location $]=$

- Belief: \#B_0009 [Hamlet believes Polonius is in the room]

- ActionInUnit: \#A_ask_01 [Hamlet asking Ophelia "Where is your father"]

- State of affairs: \#ACC_01 [Hamlet asked Ophelia about Polonius' location]

In this plan, that commits to the rhetorical question, Hamlet asks Ophelia about Polonius' location, knowing that Polonius is in the room (belief \#B_0009). Note that it is this belief that makes a standard question a rhetorical question. This plan has no real effect, since the only 
state that results is the accomplishment of this asking action. The recursive plan of Hamlet that hierarchically dominates the base plan is the following:

Rec plan: P_H_01_1 (Hamlet) [QG: Hamlet learning whether Ophelia is honest] $=$

- Belief: \#B_0009 [Hamlet believes Polonius is in the room]

- Belief: \#B_0016 [Hamlet believes Ophelia believes Polonius is in the room]

- Base plan: \#P_H_007 [Hamlet asking rhetorically Ophelia about Polonius' location]

- Base plan: \#P_O_008_1 [Ophelia tells the truth about Polonius' location]

- Belief: \#B_0017 [Hamlet believes Ophelia is honest]

This plan has two preconditions: as above, Hamlet knows that Polonius is in the room (belief \#B_0009), but he also believes that Ophelia knows that Polonius is in the room (belief \#B_0016). This double belief motivates the testing, since Hamlet can evaluate whether Ophelia is honest or not. The plan then features two subplans: the base plan above (the rhetorical question $\# \mathrm{P}_{-} \mathrm{H}_{-}$007) and a base plan of Ophelia that should tell the truth about Polonius' location (\#P_O_008_1), so allowing Hamlet to conclude that Ophelia is honest (belief \#B_0017). In this case, notice that an agent can assume the plan of another agent in her/ his plan. We know that the first (base) plan of Hamlet succeeds, while the second (recursive) plan fails because of the failure of Ophelia's plan, who will lie following the plan below.

P_O_008 (Ophelia) [PG: Ophelia lying about Polonius' location] =

- Belief: \#B_0011 [Ophelia believes Polonius is in the room]

- ActionInUnit: \#A_men_03 [Ophelia lying about Polonius' location "At home, my lord”]

- Belief: \#B_0013 [Ophelia believes Hamlet believes Polonius is at home]

In this plan, Ophelia knows that Polonius is in the room (belief \#B_0011), lies by saying "At home, my lord" (action \#A_lie_03), producing the effect that she believes that Hamlet believes the false information (belief \#B_0013), which actually is not the case. The decision of Ophelia to lie resides in a higher plan (not reported here), being concerned about her father's authority that is put at stake by Hamlet's question.

Below, we see how plans are mapped onto the timeline, to flesh out the motivations for the story evolution observed by the annotators, and to insert states into the timeline to form the AugmentedTimeline.

As an example, we see the annotation structure of the excerpt of Hamlet "nunnery" scene mentioned above (Fig. 3). As we already know, in this excerpt, Hamlet is testing Ophelia's honesty by asking rhetorically a question he knows the answer of, namely the current location of her father Polonius (actually, the same room where they are, behind a curtain), and Ophelia lies by reporting a false location, namely Polonius' home.

Going from top to bottom in the figure, the unit contains two incidents. The incident on the left (\#I_ask_01) is a process triggered by Hamlet's perform goal to ask rhetorically Ophelia about her father's location ("Where's your father?"). The schema that describes such incident is \#PS_ask, that features the Wordnet sense "testing" and the YAGOSUMO concept "Investigating"; the associated frame in Framenet is "Questioning", which requires the roles Speaker (filled by \#Hamlet), Addressee (filled by \#Ophelia), Topic (filled by \#Polonius' location), and Message (filled by the string "Where's your father?"), respectively. The schema \#PS_ask is shared by the action \#A_asr_01 of Hamlet's plan \#P_H_007 (with the three elements described above) that achieves the perform goal of "asking rhetorically". The incident on the right (\#I_lie_01) is a process triggered by Ophelia's perform goal to lie about her father's location (“At home, my lord."). The schema that describes such incident is 


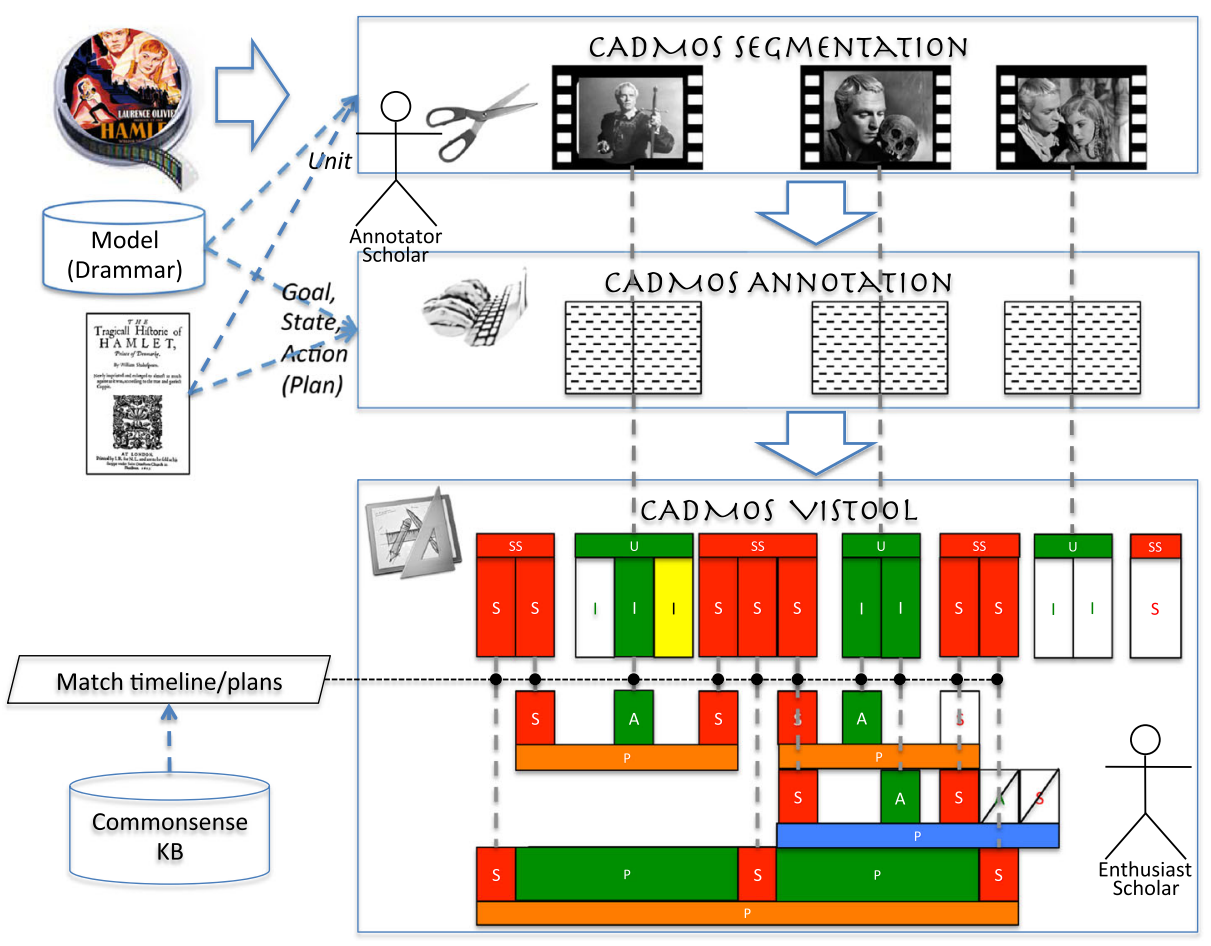

Fig. 4 The CADMOS suite workflow for unit/timeline segmentation, metadata annotation of goals, actions and plans, mapping of timeline and plans, visualization of the annotation (timeline augmented with states)

\#PS_lie, that features the Wordnet sense "deceiving" and the YAGOSUMO concept "Lie"; the associated frame in Framenet is "Prevarication", which requires the roles Speaker (filled by \#Ophelia), Addressee (filled by \#Hamlet), Topic (filled by \#Polonius' location), and Message (filled by the string "At home, my lord."), respectively. The schema \#PS lie is shared by the action \#A_lie_01 of Ophelia's plan \#P_O_008 (with the three elements described above) that achieves the perform goal of "lying". The two goals, which are in conflict, are triggered by the two values that are put at stake in this unit: for Hamlet is Honesty to be put at stake, for Ophelia the Authority of her father.

In the next section, we present the multimedia tool suite for the annotation and the visualization of the metadata illustrated here.

\section{Multimedia tool suite}

In this section, we present the CADMOS multimedia tool suite, a set of applications for the annotation and visualization of the dramatic elements in a media object. ${ }^{15}$

The workflow of the tool suite is as follows (see Fig. 4).

Given an audiovisual item, the annotator, being her/him a scholar or an enthusiast, breaks it into units (Segmentation phase), and defines a timeline of units and incidents as perceived.

${ }^{15}$ CADMOS is an acronym for Character-centred Annotation of Dramatic Media ObjectS. Project description at the http://cadmos.di.unito.it. 
Units are independently identified through the boundaries of the actions, and then incidents are identified internally. Then, he/she annotates the metadata for each unit, encoding the character's actions (i.e. the incidents forming a timeline) and the entities involved, according to the Drammar ontology (Annotation phase).

At the same time, some scholar identifies, in the original screenplay, the characters' goals and plans (intentions) that motivate the incidents above and can bridge the gap between the textual descriptions and the incidents observed by the annotator.

The result is a comparison between the timeline of incidents featured into the movie with the character's intentions into the original text (Mapping phase). Finally, the mapping plantimeline is displayed by matching the timeline incidents with the actions and plans assigned to the characters, to reveal the structure of the story plot in a visualization (Visualization phase).

Now we go through the two major phases of annotation and visualization, respectively.

\section{Video segmentation and metadata annotation}

We have developed a web based interface and annotation tool (Fig. 5), designed to carry out the encoding of the annotation in the ontology formal language, which result transparent to the annotator.

The annotation process proceeds as follows. Through the Unit menu the user creates the units, by marking its boundaries on the Video player interface.

The same Unit menu allows her/him to select existing units from a list. Once created the unit, he/she can move to the editing tabs and begin to annotate the unit generic features in the Editing area such as name, description, etc.. Then, selecting the appropriate tabs (Editing tabs), the annotator introduces the metadata for the entities of the story (agents, objects, environments - class Entity in Fig. 1. Finally, the annotator retrieves the incident templates for actions, events, and states (class Dynamics in Fig. 1); the template roles are filled with the story entities identified before. The annotation of the incidents is conducted by filling a set of templates that

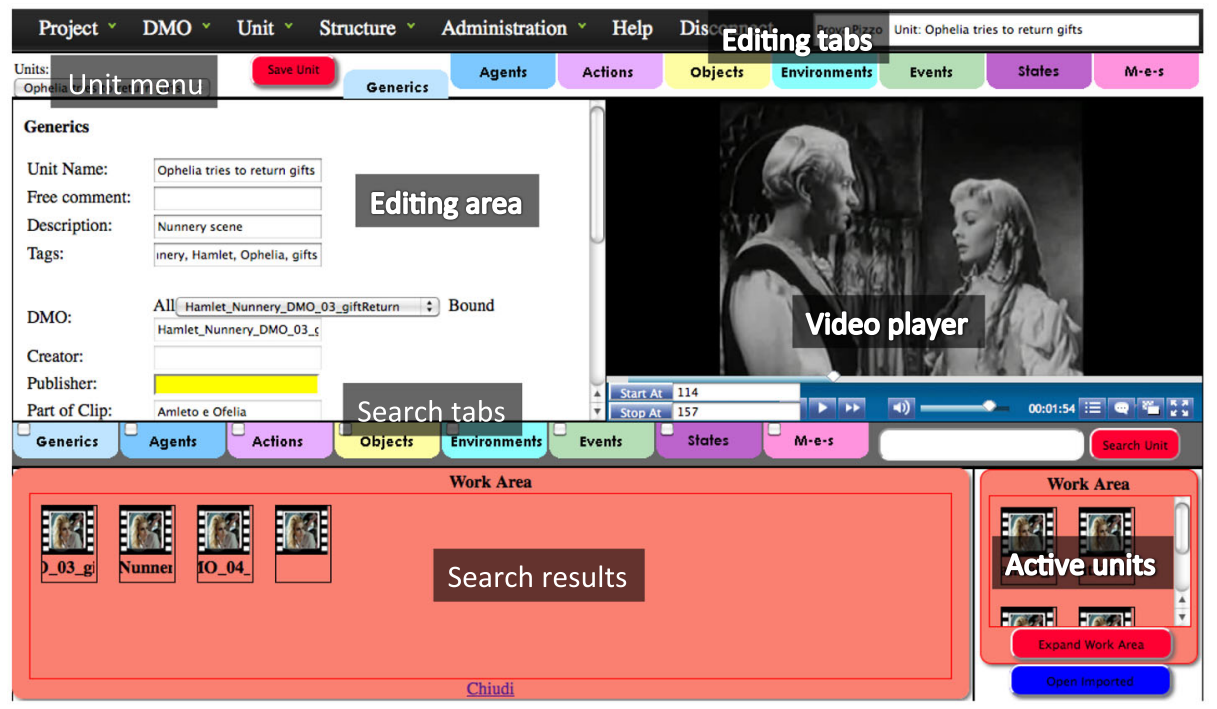

Fig. 5 The Cadmos Web Application Interface for the segmentation and the annotation phases 


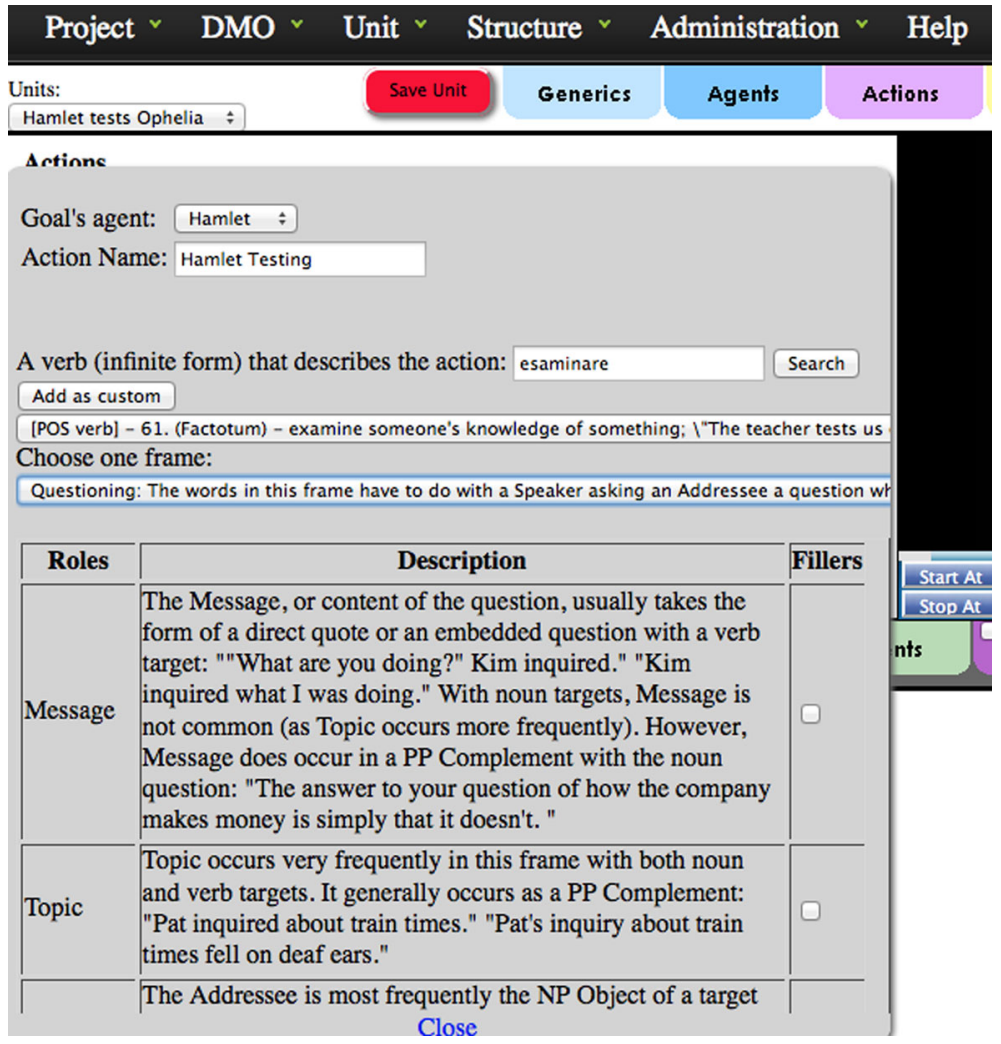

Fig. 6 Meaning negotiation in Cadmos Web application

describe the narrative elements of a unit; the appropriate templates are identified through natural language terms that are used to retrieve the template schemata in the lexical and commonsense knowledge resources. For example, in Fig. 6 we see how the annotator describes Hamlet's action "testing": he/she searches for the word (in this case, the Italian verb "esaminare"); then, he/she selects the appropriate Wordnet synset (the number 61); the system associates the frames that map such synset in Framenet; once he/she selects the frame that is the most significant for the situation (here "questioning"), the application shows the roles to be filled with the elements already annotated (agents, states, environments, object, etc.).

The web application (Fig. 5) also allows the navigation of the repository of annotated units thanks to the Search tabs. The user can perform the search by using the same features used in the unit description, and the results are shown as icons in the Search results area. We also added an active units area in which the user can keep the units whose annotation is not complete yet and needs some more work.

The web-based interface has been implemented with a client-server architecture: the client triggers AJAX/Javascript calls and receives $\mathrm{xml} / \mathrm{html}$ responses from a Java servlet, which implements classes that interface the concepts of the ontology. When the annotator inserts some metadata (e.g., some Action name) the corresponding Java class creates the fragments of the ontology that can store the related instance, connected with all the classes through the 
appropriate properties. The ontology is managed through the Owlim platform, ${ }^{16}$ a wellknown semantic repository, which offers a native RDF engine and reasoning services. The result of the annotation is an RDF graph ${ }^{17}$ that instantiates the classes and properties of the drama ontology, while the object-level elements of the story, following the paradigm of linked data [31], refer to URIs in external ontologies that describe them as commonsense knowledge concepts.

Currently, we have the following contents in our repository (cf. [37]). The complete feature film North by Northwest, a 2:30 min animation short, a 3:00 min music videoclip, a $30 \mathrm{~s}$ advertisement, an original $12 \mathrm{~min}$ movie, and the following scenes from feature films: Ride of the Valkyries (Apocalypse Now), Are You Talking Me? (Taxi Driver) Terrace scene (Matrix), Bathing at Fontana di Trevi (La Dolce Vita), The gang (A Clockwork Orange) Roy Batty monologue (Blade Runner), Carriage falling down (Battleship Potemkin) Russian roulette (The Hunter), Titles (Contempt, in French: Le Mèpris), Bet scene (The Snatch).

\section{Visualization of the dramatic qualities}

The visualization of the dramatic qualities occurs after a mapping phase, that connects the plans of the agents and the incidents of the timeline. At high level, taking as input the units and incidents that the annotator has inserted into the timeline and the plans encoded by the scholar from the original screenplay, the mapping checks what actions mentioned in the plans have been concretely realized in the timeline by establishing a correspondence with the incidents. Then, it considers the states that hold as preconditions and effects for the actions in the plan and projects them onto the units that contain the mapped incidents, in order to characterize the story advancement through the sequence of story states (snapshots of advancement). After the mapping, the visualization algorithm takes into account these correspondences and provides a diagram that informs about the dramatic qualities.

At the ontological level, the mapping phase works with the automatic reasoner provided by the ontological engine, ${ }^{18}$ which draws inferences that employ a unique SWRL IF-THEN rule (see below). A new ontological element, the Augmented Timeline, is produced from the original Timeline and the Plans that mapped the incidents. The AugmentedTimeline is an OrderedList that contains all the units and the incidents of the Timeline, in the same partial order as in the Timeline, interspersed with precondition and effect states (agglomerated into StoryStates).

Visually (see Fig. 7), if a state $S_{1}$ is a precondition of the action $A_{2}$ in the plan $P_{B 1}(\mathrm{X})$, and the action $A_{2}$ is mapped onto the incident $I_{2}$ in the Timeline, then the state $S_{1}$ is inserted in the Timeline before $I_{2}$; the same applies to effect states. These states form storystates that interleave units. The AugmentedTimeline features a total order over incidents and states.

In detail, the mapping works as follows:

- match plan actions and timeline incidents through the SWRL IF-THEN rule; this is useful for establishing the spatial alignment of the timeline incidents and the plan actions;

- point out successes and failures of characters' behaviors (i.e. plans can be fully realized, or failing): some plan actions are actually executed (as timeline incidents) and contribute to

\footnotetext{
${ }^{16} \mathrm{http}: / / \mathrm{www} \cdot$ ontotext.com/owlim.

${ }^{17} \mathrm{http} / / / \mathrm{www} . \mathrm{w} 3$ schools.com/rdf/rdf_reference.asp).

${ }^{18}$ We have used Pellet, http://clarkparsia.com/pellet/.
} 


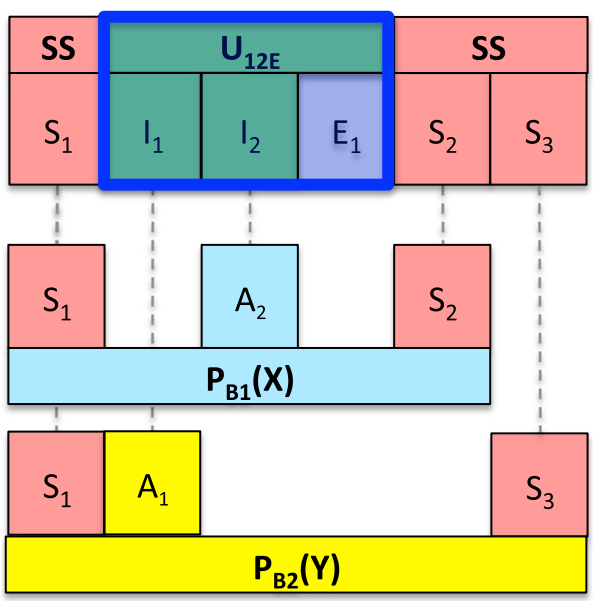

Fig. 7 How mapping works: the original annotated timeline is augmented with states projected from the plans; here are two basic plans, of two different agents, respectively providing different states to the representation. This schema is also a reference for the visualization phase

the plan success, and some plan actions result that are not executed and the plan fails to accomplish;

- project the states required by the plan, as preconditions or effects of the plan actions, onto the timeline in the places preceding or following the incidents.

- The SWRL rule is the following (syntax slightly adapted for readability issues):

- $\quad I F$

- $\quad x$ is an instance of the class ActionInPlan (subclass of Dynamics) AND

- $x$ has an precondition (property hasEffect) state $p$ AND

- $x$ has an effect (property hasEffect) state e AND

- $x$ has the same description schema of the incident $y$ of the Unit U AND

- U has a preceding StoryState $S_{p}$ and following StoryState $S S_{e}$ in the AugmentedTimeline

\section{THEN}

- $\quad p$ is inserted into the StoryState $S S_{p} A N D$

- $\quad e$ is inserted into the StoryState $S S_{e}$

The ontology is initialized with the AugmentedTimeline that is equal to the Timeline, but includes empty story states that precede and follow the units. Then, each application of the rule fills the story states with states contained in the plans.

In the excerpt of the "nunnery" scene and the plan \#P_H_007 (Hamlet), the timeline contains the actional incident, \#I_OLI_0027 (Hamlet asking Ophelia "Where is your father"), which is mapped onto the action \#A_ask_01. The same happens for the plan P_O_008 (Ophelia), between the timeline incident \#I_OLI_0028 (Ophelia lying about Polonius' location "At home, my lord") and the action \#A_men_03. The recursive plan P_H_01_1 (Hamlet) is then triggered because of the mapping of the subplan \#P_H_007 (Hamlet). 
The visualization concerns multiple trees of characters' intentions (or plans), arranged hierarchically on a tree that spans a timeline of events. The multiplicity of trees is visualized as different layers (one layer per agent per recursive depth). The abstract structure of visualization is the following. In the top row there is the Augmented Timeline, split into units (U) and story world states (SS). Units are made of incidents, which can be either intentional actions (I), so mapped to actions in agents' plans, or events (E). Story states are collections of single states, which are retrieved from the agents' plans and projected onto the timeline, to form the Augmented Timeline. There is no order within one unit, so incidents are assumed not to be ordered; clearly, also states are not ordered within a story state; the resulting order only depends upon drawing constraints. Events and unmapped incidents are colored in white (e.g. E in the second unit in Fig. 8).

In the lower part of the figure we visualize Plans of the agents, arranged hierarchically. The subscript $\mathrm{B}$ means Base, while the subscript $\mathrm{R}$ means Recursive. $X$ e $Y$ are the agents that commit to the plans; $\mathrm{S}$ is a state and $\mathrm{A}$ is an action. A Base plan consists of an action bordered by precondition and effect states, respectively; a Recursive plan consists of a sequence of

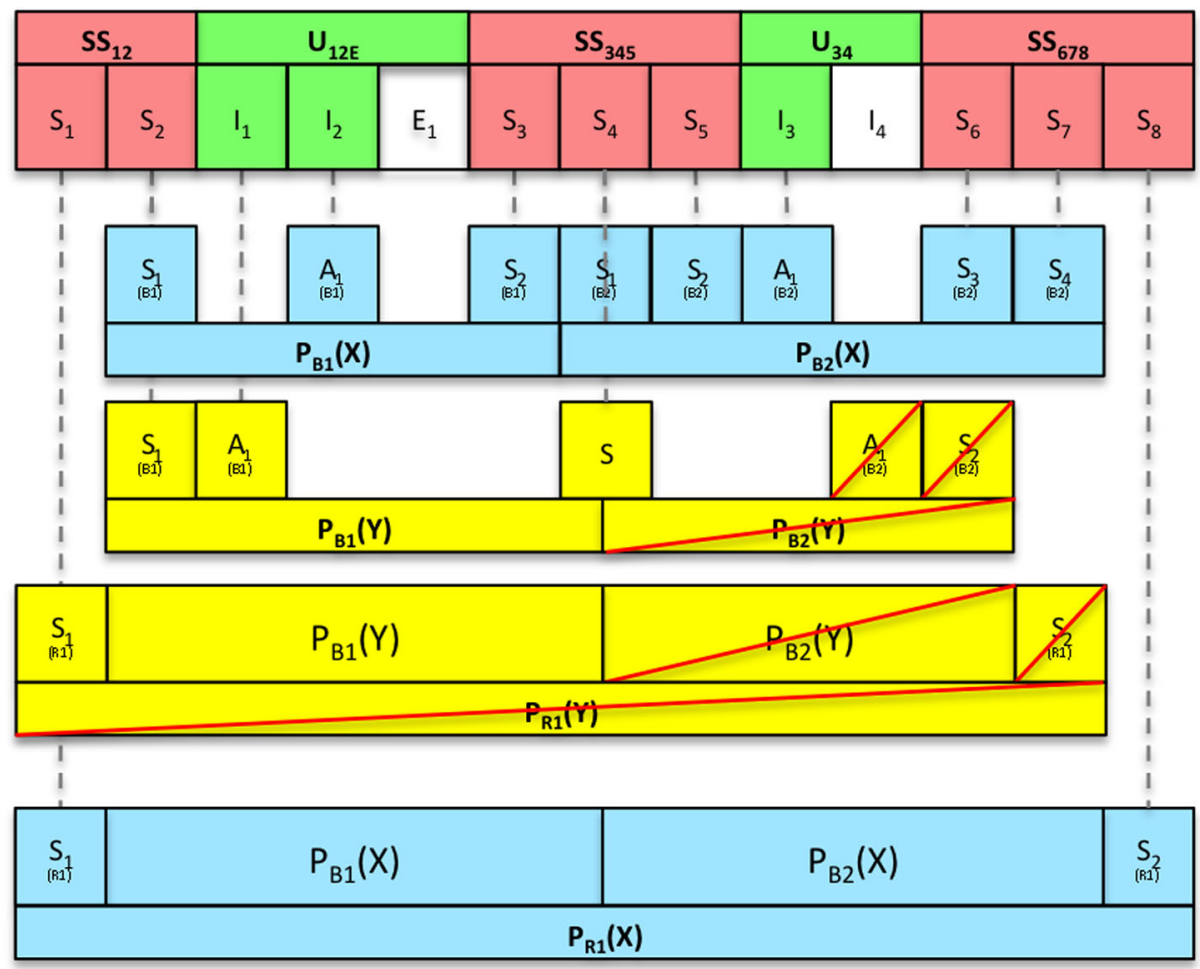

Fig. 8 General schema of the visualization: augmented timeline, made of units (made of incidents) and story states (made of states projected from plans), at the top; agents' plans, made of actions and states aligned with timeline incidents and states respectively, at the bottom 
subplans bordered again by precondition and effect states. All actions and states are mapped onto the augmented timeline, if any. Each narrative incident or state is represented by a box (green for actions, yellow for events, red for states). Finally, the boxes filled with white color and barred diagonally means have not been realized in the Timeline, thus the plan failed.

The visualization algorithm proceeds left to right by following the mapping between incidents and plan actions. It assumes the timeline distribution of the states and incidents over the $\mathrm{x}$ axis as fixed and aligns the plan actions and consequently the precondition and effect states as a consequence. The plan hierarchy is built downwards, so higher layers will be lower in the visualization. Plans fill lines close to the timeline first and as soon as the alignment does not allow to fit other plans, the algorithm goes lower in the visualization space, proceeding through layers.

Each agent features a color, which is declared in the agents' area with a clickable button. All the plans of an agent are displayed with the agent's color.

All the incidents or states in the timeline have occurred in the plot realization. The timeline incidents pivot the horizontal alignment: each realized plan action is aligned with the matching timeline incident; at the same time states of the plans are propagated to the timeline to represent the story state between adjacent units. The incidents that occur in a unit are considered in parallel, though we decided to assign them an individual position to allow for a visible alignment with the plan action. The plan label is an horizontal box that spans all the states and actions that belong to it.

Figure 9 is the visualization of the motivations of the excerpt of the "nunnery" scene incident represented in Fig. 3. The content of a box appears in a text within a balloon when the mouse goes over the box.

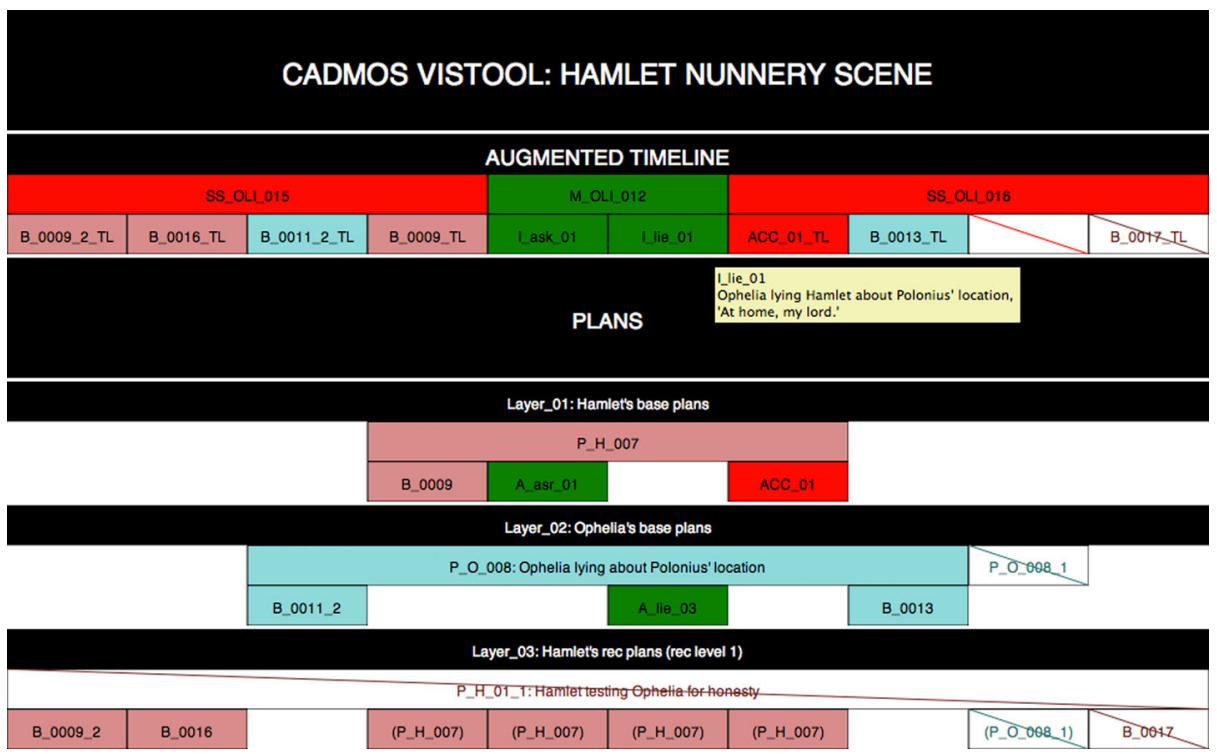

Fig. 9 Visualization of the motivations of the excerpt of Hamlet "nunnery" scene incident represented in Fig. 3. Notice the mouse-over effect for the incident \#I_lie_01, that reports the text description "Ophelia lying Hamlet about Polonius' location. 'At home, my lord'." 
The current working implementation of the visualization tool is in D3, ${ }^{19}$ after a preprocessing phase made in Processing, ${ }^{20}$ which also produces a static image. These double implementation and exit was adopted after we realized that the visualization was very slow when the diagram had a relevant size (e.g., the whole "nunnery" scene). The current D3 visualization adapts to our case the "zoomable icicle" solution" ${ }^{21}$ that provides some interactivity features for zooming on a specific area of the scene and displaying tooltips for having a synoptic view while accessing the content.

\section{Effectiveness of the multimedia tool suite}

In this section we report on the tests we carried out on the annotation and visualization tools, respectively. These preliminary experiments were aimed at validating both the feasibility of the annotation (because of the linguistic interface to the ontology), and the significance of the visualization (in comparison with the dramatic qualities listed in section 2).

\section{Annotation Test}

In this example, we report on the preliminary proof of concept for the implementation of the annotation interface, carried out on three different dramatic items, with different lengths and objectives, for reasons of coverage:

- the 2-h movie North by northwest (1959, MGM, Alfred Hitchcock), telling of an advertising man who escapes from both a criminal gang, who tries to kill him (having mistaken him for a CIA agent) and from the police, who tries to arrest him because of an unjust accuse of homicide;

- the multi-prized 2:30 min animated movie Oktapodi, about an octopus who tries to save her/his partner from being cooked after having been taken by a vendor from a fish tank;

- a humorous advertisement of the "Zippo" lighter, where a couple of gangsters try to burn a hostage, but waste all the matches they have.

The total number of units identified by each annotator was about 100, with differences due to annotators' choices for shot aggregations. Two Italian-speaking annotators inserted the annotations for the three videos; we provided guidelines to the annotators for instructing them how to behave in case of specific deficiencies of the prototype (e.g., coverage of video formats) and to avoid common attitudes (e.g., limit the use of free tags). One English-speaking annotator went through a North by northwest scene for comparison's sake.

We tested three phases of the annotation: (1) the segmentation of the video into actional units, (2) the annotation of entities and their attributes (e.g., agents' values and emotions), (3) the annotation of dynamics (with the fillers of the roles of the situation schemata). The first phase challenges the feasibility of the segmentation of the video into actional units, that is units that are determined by the beginning and end of actions. In the dramatic audiovisuals, such units exist in the screenplay writing practice (see, e.g., McKee), but shooting and editing then blur or rearrange the unit boundaries. The second phase challenges the annotation of the

\footnotetext{
${ }^{19} \mathrm{http}: / / \mathrm{d} 3 \mathrm{j}$ s.org/

${ }^{20} \mathrm{http}: / /$ processing.org/

${ }^{21} \mathrm{http} / / / \mathrm{bl}$.ocks.org/mbostock/1005873
} 
ontological concepts: the linguistic interface that we use to provide a linguistic access to the object-level ontologies can introduce differences in annotation both across languages and within a language, depending on the lexical entries selected by the annotators in the meaning negotiation phase. Also, the adoption of very large scale ontologies can introduce a high degree of ambiguity in the term selection process that can be experienced as hard by the annotators. In the experiment we have collected quantitative data of the mapping between linguistic and ontological terms and qualitative data about the annotation process itself. Finally, the third phase challenges the annotation of complex structures, with verb and nouns that are mapped onto frames and annotators that need to select the frame and distribute the roles to the entities.

All the three phases were supervised by an expert, who negotiated with the annotators the results of a first, free, annotation; this led to the revision of some decisions. This was particularly relevant for the second and third phases because of the common method (a sort of baseline) of inserting free tags (e.g., in public repositories), indeed a very immediate way to annotate story units; so, the introduction of a structured method always poses the challenge of being too sophisticate and hence rejected by the actual users. However, once the annotation section has been selected (agent, object, environment, action, event, state), we allow the annotator the possibility to annotate with free tags too (thus only providing a shallow structure over tags).

The segmentation phase, i.e. the detection of boundaries of units, was carried out through the video player, by inserting markers for the boundaries and then saving the units. In this phase, it was interesting to note that there was a significant consistency in the boundary identification.

For the feature film North by northwest, segmented in about 80 units, we found that $45 \%$ of units coincide exactly; of the remaining units, $84 \%$ of them were contained in some coincident unit in the other segmentation, (i.e., one of the annotators was more refined in the segmentation), and $16 \%$ overlapped with the adjacent ones. After the supervised negotiation, almost $90 \%$ of units could be considered coincident. These numbers resulted from a tolerance of about $40 \mathrm{~s}$ on the boundary comparison, a reasonable threshold on a 2-h feature film.

For the short animation Oktapodi, where one annotation has segmented 10 units and the other only 3 , the coincidence was of $45 \%$, with a $33 \%$ of internal subdivision on the remaining units (boundaries coincidence includes a 5 -s tolerance, $78 \%$ of coincidence after negotiation).

Finally, the 30-s advertisement Zippo was segmented in 3 and 4 units, respectively, with $83 \%$ of coincidence, and $100 \%$ if we consider inclusion between segments (tolerance $1 \mathrm{~s}$ ).

So, we can conclude that the segmentations conducted by different humans do not show relevant differences. In fact, if guidelines clearly state that the units must be segmented on a actions/event base, i.e. following the start and the end, respectively, of an action/event, the number and length of the segmented units will result consistently similar, and there is no need of a relevant revision by the supervisor.

The second phase is when the annotator selects ontological concepts to describe the entities and their attributes. Because we fear that this may likely introduce a large inter-language and inter-annotator variety of terms, we conducted a preliminary survey to measure the amount of mappings that were present between the linguistic knowledge bases, MultiWordnet and Wordnet, with the concept ontology YAGOSUMO. MultiWordnet contains about more than 100,000 English synsets and almost 40,000 Italian synsets. ${ }^{22}$

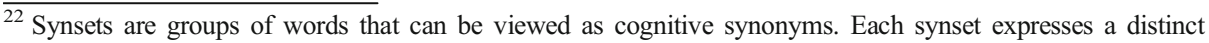
concept.
} 
Table 1 Number of mappings between MultiWordnet and YAGO-SUMO terms (English (a) and Italian (b))

(a) English Terms

$\begin{array}{llllll} & \text { Total Synsets } & \text { Verbs } & \text { Nouns } & \text { Adjectives } & \text { Adverbs } \\ \text { Total MWN } & 102101 & 12144 & 68465 & 17917 & 3575 \\ \text { Mappings to YAGOSUMO } & 94817 & 10452 & 64831 & 16062 & 3472 \\ \text { Percentage } & 92.86 & 86.06 & 94.69 & 89.64 & 97.11\end{array}$

(b) Italian Terms

Total MWN

Mappings to YAGOSUMO

Percentage

\begin{tabular}{lllll} 
Total Synsets & Verbs & Nouns & Adjectives & Adverbs \\
38653 & 4985 & 28517 & 3911 & 1240 \\
30937 & 4332 & 21752 & 3643 & 1210 \\
80.03 & 86.90 & 76.27 & 93.14 & 97.58 \\
\hline
\end{tabular}

Tables 1 (a) and (b) report the statistics for English and Italian terms, respectively. $92.86 \%$ of the English terms reported in MultiWordNet (80.03\% for Italian terms) allow the user to leverage the ontological mappings provided by the system, without any knowledge about the ontological knowledge base itself. In fact, the presented system provides a guided access to the ontological concepts related to more than $90 \%$ of the English words and $75 \%$ for Italian (with difference over categories). For languages other than English, the percentages are lesser because of the yet incomplete integration of the several knowledge bases. In our web application the considered ontologies are expressed in English (see Fig. 6), and the system finds the correspondent concepts by starting from glosses in different languages.

Then, we computed the inherent ambiguity in the linguistic knowledge bases MultiWordnet and Wordnet (see Table 2), which is less than 2 on average (i.e., for each linguistic term, the system retrieves in average less than 2 definitions). Given a total number of 289 requests, we found that the users had to disambiguate in average among $2.83 \%$ terms. This means that the annotators tend to use linguistic terms that are more generic than the average.

We also ran a qualitative analysis about the difficulty of inputing the appropriate linguistic term and the consequent selection of the adequate definition. We asked the annotators to fill up a questionnaire with the following information:

1. Was it subjectively hard to make a selection from the list of definitions? The answers to this question were: 231 Easy (80\%), 39 Medium (13.5\%), 19 Hard (6.5\%).

2. How many times did you revise your choice by searching for a synonym? The answers were: never 206 times (61\%), once 87 times (26\%), twice 32 (9\%), three times $10(3 \%)$, four times 4 (1\%); so 2 or more is about the $13 \%$ of cases.

Table 2 Inherent semantic ambiguity: the average number of definitions that the system retrieves for the annotator (for disambiguation) (a) for each English term, (b) for each Italian term

(a) English Terms

$\begin{array}{lllll}\text { Avg ENG } & \text { Avg Nouns } & \text { Avg Verbs } & \text { Avg Adjectives } & \text { Avg Adverbs } \\ 1.70 & 1.74 & 1.82 & 1.69 & 1.59\end{array}$

(b) Italian Terms

\begin{tabular}{lllll} 
Avg ITA & Avg Nouns & Avg Verbs & Avg Adjectives & Avg Adverbs \\
1.73 & 1.70 & 1.82 & 1.69 & 1.59 \\
\hline
\end{tabular}


3. How many times did you change your interpretation because of the definitions proposed by the system? This happened 48 times out of $289,17 \%$ of cases.

4. How many times did you resort to free text, giving up the search of an ontological concept? This happened 21 times out of $289,7 \%$ of cases.

From these data we can conclude that the task of selecting an ontological concept through linguistic definitions is not hard, and the interface system is adequate for supporting the task.

Finally, the third phase concerns the selection of frames (to provide a structure for the incidents) and the assignment of filler entities to roles in linguistic frames. We tested the ambiguity factor in the selection of frames to be assigned as templates of some action/event in a unit. Preliminarily, we measured the amount of mappings that were present between the linguistic knowledge bases, MultiWordnet and Wordnet, with the frame knowledge base FrameNet (VerbNet only indicates generic roles). Table 3 shows that numbers for frames (22\% for the total of English synsets) are significant for verbs (60\% for English and $70 \%$ for Italian). Therefore, in the guidelines we advised annotators to describe processes and states with verbs.

The average number of frames retrieved per term in MultiWordnet is slightly above one (Table 4), therefore there is almost no ambiguity.

Again, we asked the annotators to fill up a questionnaire about the difficulties encountered in annotating the frame, thus providing a structure for the events occurring in the unit. These were the results.

5. How many times did you find the correct frame (exclude the Verbnet thematic roles)? The answer was 151 out of $246(61 \%)$. So, 95 times (39\%) the annotators inserted the generic frame.

6. Was it subjectively hard to assign the frame roles to agents and objects? No doubt and immediate selection occurred 106 times out of 175 (61\%); hesitant on two entries for a role occurred 53 times out of 175 (30\%); mulling over a lot without finding the right assignment and then settled for one occurred 16 times out of $175(9 \%)$.

After the experiment, we measured the total of ontological concepts and frames that overlap. Before supervision, overlapping concepts were $35 \%$ and the overlapping frames were $37 \%$. Beyond individual differences of annotation, these numbers also depend on the different granularities of unit detection (larger units tend to be annotated with broader concepts - e.g., searching instead of chasing) and the repetitions employed by the annotators in the

Table 3 Number of mappings between MultiWordnet and FrameNet terms (Italian (a) and English (b))

(a) English Terms

$\begin{array}{llllll} & \text { Total Synsets } & \text { Verbs } & \text { Nouns } & \text { Adjectives } & \text { Adverbs } \\ \text { Total MWN } & 102101 & 12144 & 68465 & 17917 & 3575 \\ \text { Mappings to FrameNet } & 22351 & 7193 & 10258 & 4352 & 548 \\ \text { Percentage } & 21.89 & 59.23 & 14.98 & 24.28 & 15.32\end{array}$

(a) Italian Terms

\begin{tabular}{llllll} 
& Total Synsets & Verbs & Nouns & Adjectives & \multicolumn{1}{c}{ Adverbs } \\
Total MWN & 38653 & 4985 & 28517 & 3911 & 1240 \\
Mappings to FrameNet & 12357 & 3643 & 7252 & 1212 & 250 \\
Percentage & 31.96 & 73.07 & 25.43 & 30.98 & 20.16 \\
\hline
\end{tabular}


Table 4 Inherent frame ambiguity: the average number of frames (a) for each English synset, (b) for each Italian synset

(a) English Terms

$\begin{array}{lllll}\text { Avg ENG } & \text { Avg Nouns } & \text { Avg Verbs } & \text { Avg Adjectives } & \text { Avg Adverbs } \\ 1.10 & 1.04 & 1.23 & 1.03 & 1.59 \\ \begin{array}{l}\text { a) Italian Terms } \\ \text { Avg ITA }\end{array} & \text { Avg Nouns } & \text { Avg Verbs } & \text { Avg Adjectives } & \text { Avg Adverbs } \\ 1.17 & 1.09 & 1.46 & 1.04 & 1.10\end{array}$

annotation of long audiovisuals, such as a feature film (i.e., a term that has been successful in the description of a previous unit will be re-used). These attitudes increase the gap over annotators. After supervision, and the propagation of its effects over the whole annotation, the overlapping of concepts and frame doubled (around $70 \%$ ).

It is worth noting that the supervision phase has to be very careful in distinguishing between cases when the annotator disagreement results from a lack of accuracy of the annotator or from a genuine difference in the intentions of the annotators. During the discussions, the supervisor must be able to negotiate between the homogenization of the annotations, thus favouring the performance of machine learning methods in discovering interesting properties of the story, and the acceptance of multiple different annotations, thus favouring the diversity of interpretations and the argumentations of scholars and students about some unit interpretation. We assembled some guidelines for the supervisor; both the annotation will likely be useful in different tasks, and only further applicative experiment will solve such an issue.

\section{Visualization test}

In this section, we evaluate in a qualitative way the visualization interface described above. In particular, we address the use of the interface in teaching drama to students and to quickly flesh out interesting aspects of the story.

In the last decades, the drama courses focus has switched from literary to structural and actional qualities. This means that the script is more and more intended both as an incident design (either on stage or on screen) and as a network of relations over agents' intentions. For example, McKee [41] guides the author through the scene, splitting the beats according the character's actional goal, and its value change.

This trend leads to a larger use of visualization systems to clearly stress the structural elements in the dramatic text, and to map the connection with the performance, i.e., to show the continuity between incident design and incident performance. For example, the drama map provided by the ReadWriteThink website ${ }^{23}$ allows the students to focus on the elements of the drama, posing key questions about the conflict's structure. ${ }^{24}$.

Our interactive system steps forward and visualizes both the agents' intentions and their mapping onto the timeline. Within the educational framework, where the main task is learning about drama structure and meaning, our visualization helps to bridge the gap between the description of a script and a given performance. Furthermore, it shows the interventions of the latter in terms of dramaturgy. ${ }^{25}$ To test the effectiveness of our model, we asked a postgraduate

\footnotetext{
23 http://www.readwritethink.org/

$24 \mathrm{http} / /$ www.readwritethink.org/classroom-resources/student-interactives/drama-30012.html?tab=2\#tabs

${ }^{25}$ Nevertheless our visualization could be more effective if the timeline were expressed also in terms of frames and timecode to give teachers and students a more direct access to the audiovisual document.
} 
Table 5 Number of units and conflicts in the "nunnery" scene

\begin{tabular}{lllll}
\hline & Length in mins & N. of units & N. of conflicts & $\%$ \\
\hline Olivier & 235 & 33 & 9 & 27,2 \\
Zeffirelli & 168 & 35 & 8 & 22,8 \\
Branagh & 306 & 43 & 11 & 25,6 \\
\hline
\end{tabular}

student, in a master thesis project, to analyze different versions of a single scene from three movies based on Hamlet, respectively the ones directed by Olivier, Zeffirelli, and Branagh. Once the student has annotated the three clips according the Drammar ontology, we have analyzed the results.

Table 5 compares the three scene in terms of length (that is a given data), number of units and conflicts detected by the annotator. First we note that Olivier's version has a lower number of units but is considerably longer that the Zeffirelli's version, and shows one conflict more. This tells the student that Zeffirelli has chosen to carry out a tightened pace Hamlet, where the Prince of Denmark is performed by Mel Gibson (famous for his action movies), and thus described as determined, athletic, dynamic. On the contrary, Olivier's version focuses on the inner feelings of the character, leading to a slower pace and focusing on a higher level of interpersonal conflicts. Finally Branagh's "nunnery" scene seems to take a balance with respect to the other two. It is the longest scene, but has also the high number of units and conflict. This means that Branagh's version shows both a fast action pace and an attention to the characters' conflicts. In Table 6 we report the list of emotions that were detected by the annotator according our ontology model taken from [45] emotion types. The emotions are listed for each version of the scene, following the temporal sequence, for each character. We note that Olivier's version has the highest number of emotion detected and, moreover, the highest diversification: in 5 moments of the scene the characters feel different emotions. Furthermore Hamlet goes from Love to Anger thus representing a significant change in his mental status. Therefore the student can understand how Olivier focuses on the inner psychological implication of the scene. Till here, we have tested the effectiveness of our model of drama that lays behind the multimedia tool suite. In other words, if you teach to the class to describe a drama according our ontological model, the result will be that some key feature of the drama will be clearly outlined, and will be easily compared with others drama.

Table 6 From top to bottom, the sequence of Hamlet and Ophelia's emotions in the "nunnery" scene

\begin{tabular}{llllll}
\hline \multicolumn{2}{c}{ Olivier } & \multicolumn{2}{c}{ Zeffirelli } & \multicolumn{2}{c}{ Branagh } \\
Hamlet & Ophelia & Hamlet & Ophelia & Hamlet & Ophelia \\
Love & Distress & Distress & Distress & Happy-for & Happy-for \\
Distress & Happy-for & Anger & Hope & Love & Love \\
Pride & Pride & Reproach & Reproach & Distress & Distress \\
Reproach & Disappoint. & Love & Disappoint. & Anger & Disappoint. \\
Hope & Reproach & Fear & Anger & Reproach & Reproach \\
Anger & Hope & & Pride & Disappoint. & Fear \\
& Fear & & Fear & Hope & Pity \\
& Pity & & & Resentment & \\
\end{tabular}




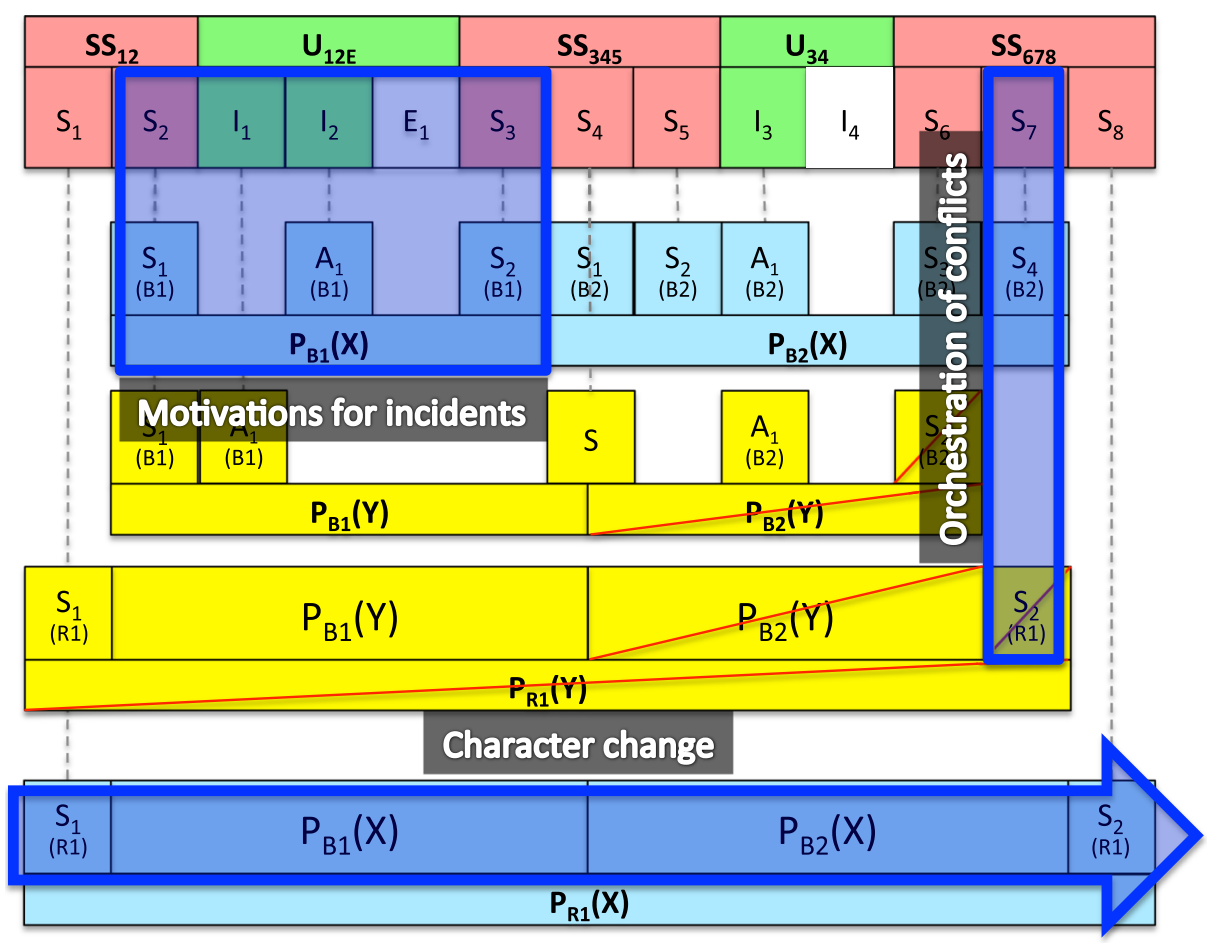

Fig. 10 Interpretation of the visualization

Now we describe what the class can learn from the kind of visualization provided by our multimedia tool suite. In Fig. 10 we propose a schema of how to interpret the actual visualization of an annotated example (as in Fig. 9). In general, our visualization helps the class to understand how the text of the dramatic medium is bound to the character's deliberation, and thus how to read the characters' behaviors. For example, the more successful the mappings, the more the narrative text of the dramatic medium is bound to characters' deliberation (i.e. the performance is consistent with the play). Therefore, our system can be used as a qualitative evaluation tool both in teaching drama authoring and in drama analysis. In Fig. 10 we highlight three examples of how our system can visualize some key features of drama.

\section{Motivation for incidents}

In drama is important that the character's plans show some consistency with the incidents that occur in the sequence of events. This is the fundamental feature that gives to the audience the perception of a logical sequencing of action, thus helps to create the believability of the story in terms of consistent list of incidents within the units (see Units in Section 2). In our visualization (the highlighted area in the top of the Fig. 10) the list of incidents is grounded on the perceived behaviors of the agents involved. In other words, it is graphically clear how the list of incidents in unit $\mathrm{U}_{12 E}$ are connected with the action in plan $\mathrm{P}_{B 1}(\mathrm{X}) .^{26}$

${ }^{26}$ In Fig. 10, $(\mathrm{X})$ and $(\mathrm{Y})$ represent two different characters 


\section{Orchestration of conflicts}

Normally the units listed in the timeline are the results of the synchronous happening of the two agents' plans (such as the ones by Hamlet and Ophelia in the "nunnery" scene). We adopt a visualization that shows a layer of parallel plans that map onto the same chunk of the timeline. When the two plans have a similar goal, they both aim at the same effect: thus they map the same final state onto the timeline, and are described as shared plan. Our visualization can also pile up different plans with opposite goals. When this occurs, likely it means that only one plan will achieve its goal and thus only one state is mapped onto the timeline. In the highlighted area in the right of the Fig. 10 we see that planP $\mathrm{P}_{B 2}(\mathrm{X})$ and plan $\mathrm{P}_{B 2}(\mathrm{Y})$ span the same chunk of timeline (unit $\mathrm{U}_{34}$ ). Yet the state $\mathrm{S}_{4(B 2)}$ in plan $\mathrm{P}_{B 2}(\mathrm{X})$ is mapped on state $\mathrm{S}_{7}$ onto the timeline, while the state $\mathrm{S}_{2(R 1)}$ doesn't: this is graphically shown as barred box. If a state is barred, this means also that the plan that intended to achieve that state is failed (hence barred). This means that there is a conflict between the agents. Our visualization provides a clear image of the orchestration of conflicts and their execution (see Conflict in Section 2).

\section{Change}

In drama, character's plan failure is normally evaluates through an emotional appraisal and is the reason for the character's re-deliberation. For example, in the "nunnery" scene, the failure of the Hamlet's plan is a clear indication of the emotional characters' change. This is normally one of the key figures into the emotional engagement of the audience. The highlighted area at the bottom of the Fig. 10 represents how the character changes as a sequence of characters' planning and re-planning, thus stress the emotional charge of the drama (see Emotion in Section 2).

Other significant features should be added to the visualization, namely the Dramatic Arc and a dynamic/interactive construction of the mapping. This is left for future work.

\section{Conclusion}

In this paper, we have presented a system for the annotation of metadata that can encode the intangible heritage provided by a drama and for the graphic visualization of the dramatic qualities to support drama analysis and didactics. The paper has stressed the importance of the intangible knowledge about a drama, beyond the different representations (tangible heritage) that can be produced, and identifies from the drama literature the qualities that constitutes a drama. The computational ontology Drammar encodes the knowledge about the dramatic qualities: in particular, the ontology encodes the notions of action, agent (or character), conflict, dramatic arc, unit, and emotion. The major issue is the connection of the agent's intentions with the action she/he carry on in the drama. Then, the paper has illustrated the multimedia tool for the annotation of the metadata and the visualization module that graphically arranges the several elements of the drama. The system was tested on the analysis and exposition of the case of a short classical scene in Hamlet for testing the effectiveness of the annotation and the visualization tasks.

The annotation tool is a web-based application that relies on a video player, with capabilities of marking the boundaries of video segments, and a number of editing areas, for the introduction of the annotation terms through a linguistic interface. The visualization module maps the characters' intentions of dramatic plot onto the timeline's incidents of the performance. Character's intentions 
form multiple trees that span a timeline of incidents; the system is able to build the mapping between a library of plans and the timeline of incidents, and to visualize the contributions of the several characters' intentions to the whole plot.

Finally, we have tested the multimedia tool suite with respect to its effectiveness for the annotation of the dramatic items and the visualization of the dramatic qualities in analysis and teaching. The tests have shown that the linguistic interface is effective for the annotation task, through statistics over the selection tasks, and a questionnaire about the annotator experience. The mapping and visualization task have shown to be effective in pointing out the emotional charges of the drama actions and illustrate the evolution of the drama; this is relevant in both analysis and didactics.

The method can be improved in several ways. Building on the current framework, we would like to apply automatic methods for unit splitting and marking, deriving from video indexing methods; moreover, we would like to implement a more interactive workflow, by supporting the annotators with on-the-fly proposal of annotation, based on simple reasoning services (e.g., a dead man state should follow an action of killing); finally, the visualization module should be integrated within the web-based platform, to support again the annotators in detecting what is already annotated and what is required next.

In the future, we aim at building the analysis upon the unrestricted annotation provided by narrative enthusiasts and media students on the web platform. The final aim is the construction of a community of annotators that can contribute to a large repository of annotated stories, thus enriching dramatic media heritage and also preserving the intangible heritage of drama in general.

We also aim at applying the method to professional scenarios within the media industry, such as the dramatic media production, the analysis of news stories and blog entries, and the fruition of cultural heritage through web and mobile applications. For example, our system could interactively support the trace and measure of the consistence between the screenplay and final product in the film production pipeline.

\section{References}

1. Addison AC, De Luca L, Guidi G, Pescarin S (eds) (2013) 2013 Digital Heritage International Congress, vol 2, Institute of Electrical and Electronics Engineers

2. Agirre E, Barrena A, de Lacalle OL, Soroa A, Fernando S, Stevenson M (2012) Matching cultural heritage items to wikipedia. In: Chair) NCC, Choukri K, Declerck T, Doğan MU, Maegaard B, Mariani J, Odijk J, Piperidis S (eds) Proceedings of the Eight International Conference on Language Resources and Evaluation (LREC'12), European Language Resources Association (ELRA), Istanbul, Turkey

3. Aristotele (2008) Poetica. Einaudi

4. Aristotle (2013) Poetics. Oxford University Press

5. Baikadi A, Goth J, Mitchell CM, Ha EY, Mott BW, Lester JC (2011) Towards a computational model of narrative visualization. In: AIIDE 2011 - AAAI Workshops at the Seventh Artificial Intelligence and Interactive Digital Entertainment Conference, pp 2-9

6. Baker C, Fillmore C, Lowe J (1998) The berkeley framenet project. In: Proceedings of the 36th Annual Meeting of the Association for Computational Linguistics and 17th International Conference on Computational Linguistics-Volume 1, Association for Computational Linguistics, pp 86-90

7. Bellini P, Nesi P, Serena M (2011) MyStoryPlayer: Semantic audio Visual Annotation and Navigation Tool. In: The 17th International Conference on Distributed Multimedia Systems, Florence, URL http://www.ksi. edu/seke/Proceedings/dms11/DMS/23_Pierfrancesco_Bellini.pdf

8. Bordwell D, Thompson K (2006) Film art : an introduction. McGraw Hill, Boston

9. Bratman M (1987) Intention, Plans, and Practical Reason. Harvard University Press, Cambridge

10. Brooks C, Heilmann RB (1946) Understanding Drama. G.G. Harrap

11. Bruner J (1991) The narrative construction of reality. Crit Inq 18(1):1-21

12. Card SK, Suh B, Pendleton B, Heer J, Bodnar JW (2006) Timetree: Exploring time changing hierarchies. In: IEEE Symposium on Visual Analytics Science and Technology (VAST) 
13. Carlson M (1984) Theories of the theatre : a historical and critical survey from the Greeks to the present. Cornell University Press, Ithaca

14. Carroll N (2001) Beyond Esthetics: Philosophical Essays. Cambridge University Press, New York, Cambridge

15. Carson C (1997) Drama and theatre studies in the multimedia age:'reviewing the situation'. Literary and Linguistic Computing 12 (4):269-275, DOI 10.1093/llc/12.4.269, URL http://llc.oxfordjournals.org/content/ 12/4/269.abstract, http://llc.oxfordjournals.org/content/12/4/269.full.pdf + html

16. Cataldi M, Damiano R, Lombardo V, Pizzo A (2012) Lexical mediation for ontology-based annotation of multimedia. In: Oltramari A, Vossen P, Qin L, Hovy E (eds) New Trends of Research in Ontologies and Lexical Resources, Theory and Applications of Natural Language Processing Series, Springer

17. De Melo G, Suchanek F, Pease A (2008) Integrating yago into the suggested upper merged ontology. In: Tools with Artificial Intelligence, 2008. ICTAI'08. 20th IEEE International Conference on, IEEE, vol 1, pp 190-193

18. Diderot D (1966) Selected Writings. Classics in the history of thought. Crocker L (ed.), Macmillan, URL http://books.google.it/books?id=RJBcAAAAMAAJ

19. Egri L (1946) The Art of Dramatic Writing. Simon and Schuster, New York

20. Elam K (1980 (1987)) The Semiotics of Theatre and Drama. Methuen, London and New York

21. Elson DK (2012) Dramabank: Annotating agency in narrative discourse. In: Proceedings of the Eighth International Conference on Language Resources and Evaluation (LREC 2012), Istanbul, Turkey

22. Esslin M (1988 (1987)) The Field of Drama. Methuen, London

23. Field S (2003) The definitive guide to screen writing. Ebury Press, London

24. Fisher D, Hoff A, Robertson GG, Hurst M (2008) Narratives: A visualization to track narrative events as they develop. In: Proceedings of the IEEE Symposium on Visual Analytics Science and Technology (IEEE VAST 2008), Columbus, Ohio, USA, vol 01

25. Freytag G (2004) Technique of the Drama: An Exposition of Dramatic Composition and Art. University Press of the Pacific

26. Gangemi A, Presutti V (2009) Ontology design patterns. Handbook on Ontologies 221-243

27. Genette G (1983) Narrative Discourse: An Essay in Method. Cornell University Press

28. Graham M, Kennedy JB (2010) A survey of multiple tree visualisation. Inf Vis 9(4):235-252

29. Guarino N, Oberle D, Staab S (2009) What is an ontology? In: Handbook on Ontologies, 2nd edn, Springer

30. Hatcher J (1996) The Art and Craft of Playwriting. Story Press, Cincinnati

31. Heath T, Bizer C (2011) Linked data: Evolving the web into a global data space. Synthesis Lectures on the Semantic Web: Theory and Technology pp 1-136

32. Hegel G (1885) Hegel's Aesthetics. S.C. Griggs and Company

33. Kipper K (2005) VerbNet: A broad-coverage, comprehensive verb lexicon. PhD Thesis, University of Pennsylvania

34. Kurin R (2004) Safeguarding intangible cultural heritage in the 2003 UNESCO convention: a critical appraisal. Museum International 56 (1/2):66-77, URL http://search.ebscohost.com/login.aspx?direct= true\&\#38; $\mathrm{db}=$ aph\&\#38;AN=13537907\&\#38; site=ehost-live

35. Lavandier Y (1994) La dramaturgie. Le clown et l'enfant, Cergy

36. Lessing GE (1962) Hamburg Dramaturgy. Dover Publications

37. Lombardo V, Damiano R (2012) Commonsense knowledge for the collection of ground truth data on semantic descriptors. In: Proceedings of the 2012 I.E. International Symposium on Multimedia (ISM 2012), IEEE Computer Society, pp 78-83

38. Lombardo V, Pizzo A (2013) Ontologies for the metadata annotation of stories. In: Digital Heritage, ACM, Marseille, France

39. Mamber S (2003) Narrative mapping. In: Caldwell J (ed) Everett A. New Media, Routledge, pp $145-158$

40. Mamet D (1998) Three Uses of the Knife: On the Nature and Purpose of Drama. The Columbia Lectures on American Culture, Columbia University Press, URL http://books.google.it/books?id=YZRODCVYACsC

41. McKee R (1997) Story. Harper Collins, New York

42. Miller G (1995) Wordnet: a lexical database for english. Commun ACM 38(11):39-41

43. Naphade M, Smith JR, Tesic J, Chang SF, Hsu W, Kennedy L, Hauptmann A, Curtis J (2006) Large-scale concept ontology for multimedia. IEEE MultiMedia 13:86-91

44. Norling E, Sonenberg L (2004) Creating Interactive Characters with BDI Agents. In: Proceedings of the Australian Workshop on Interactive Entertainment IE2004

45. Ortony A, Clore G, Collins A (1988) The Cognitive Structure of Emotions. Press, Cambrigde

46. Pease A, Niles I, Li J (2002) The suggested upper merged ontology: A large ontology for the semantic web and its applications. In: Working Notes of the AAAI-2002 Workshop on Ontologies and the Semantic Web, Edmonton, Canada, vol 28 
47. Peinado F, Cavazza M, Pizzi D (2008) Revisiting Character-based Affective Storytelling under a Narrative BDI Framework. In: Proc. of ICIDIS08, Erfurt, Germany

48. Pfister M (1991) The Theory and Analysis of Drama. European Studies in English Literature, Cambridge University Press, URL http://books.google.it/books?id=2BxOGkheiHMC

49. Pianta E, Bentivogli L, Girardi C (2002) Multiwordnet: developing an aligned multilingual database. In: Proceedings of the First International Conference on Global WordNet, URL http://multiwordnet.fbk.eu/ paper/MWN-India-published.pdf

50. Polti G (1895) Les trente-six situations dramatiques. Mercure de France, Paris

51. Propp V (1968) Morphology of the Folktale. Press, Texas

52. Rimmon-Kenan S (1983) Narrative Fiction: Contemporary Poetics. Routledge

53. Ryan M (2006) Avatars of Story. Press, Minnesota

54. Ryngaert J (2008) Introduction à l'analyse du théâtre. Collection Cursus. Série Littérature, Armand Colin, URL http://books.google.it/books?id=WldsIAAACAAJ

55. Smith GM (2003) Film Structure and the Emotion System. Cambridge University Press, Cambridge

56. Smith L, Akagawa N (2008) Intangible Heritage. Key Issues in Cultural Heritage, Taylor \& Francis, URL http://books.google.it/books?id=voan0ESUzgAC

57. Snoek CG, Worring M, van Gemert JC, Geusebroek JM, Smeulders AW (2006) The challenge problem for automated detection of 101 semantic concepts in multimedia. Proceedings of ACM Multimedia, Santa Barbara, pp 421-430

58. Spencer S (2002) The Playwright's Guidebook: An Insightful Primer on the Art of Dramatic Writing. Faber \& Faber, URL http://books.google.it/books?id=nDrHmckSqi4C

59. Strauss A, Corbin J (1990) Basics of qualitative research: grounded theory procedures and techniques. Sage Publications, Calif

60. Suchanek F, Kasneci G, Weikum G (2007) Yago: a core of semantic knowledge. In: Proceedings of the 16th international conference on World Wide Web, ACM, pp 697-706

61. Szondi P (1983) Theory of the moderna drama parts i-ii. boundary 211 (3):191-230

62. van Riemsdijk M, Dastani M, Winikoff M (2008) Goals in Agent Systems: A Unifying Framework. In: Proceedings of AAMAS'08

63. Vecco M (2010) A definition of cultural heritage: From the tangible to the intangible. Journal of Cultural Heritage 11 (3):321 - 324, DOI10.1016/j.culher.2010.01.006, URL http:/www.sciencedirect.com/science/ article/pii/S1296207410000361

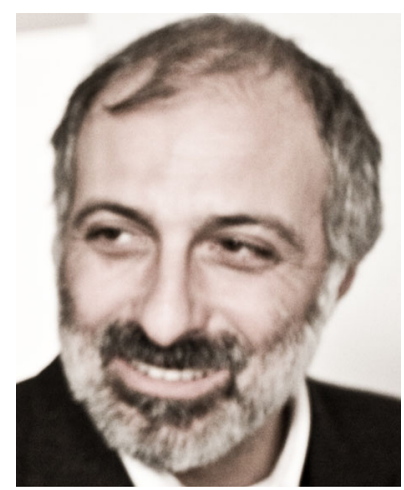

Vincenzo Lombardo PhD Associate Professor of Informatics Department of Informatics, University of Turin, Italy (www.di.unito.it/ vincenzo). Born in 1964, he graduated in Computer Science at the University of Turin (1987), and doctorated in Computer Science in the Turin-Milan University Consortium (1993). He is co-founder and current President of CIRMA (Centre for Research on Multimedia and Audiovisuals - www.cirma.unito.it) and teaches at the School of Media and Arts of the University of Torino. He is in the PhD Committee of the Computer Science programme of the Doctoral School Doctoral School of Sciences and Innovative Technologies (http://dottsnti.campusnet.unito.it/do/home.pl). He has been the coordinator of the EU-funded project Virtual Electronic Poem (www.edu.vrmmp.it/vep/) and of the national project DramaTour (www.dramatour.unito.it), and the projects CADMOS (www.cirma.unito.it/cadmos) and be the WP leader in several national projects (www. atlas.polito.it/en/). At the Virtual Reality \& Multi Media Park company (www.vrmmp.it), he has been running (2005-2012) the Art-Science Alliance Laboratory (ASA Lab - http://www.vrmmp.it/?page_id5=597), for applied 
research projects in interactive multimedia, and the School (www.edu.vrmmp.it), with training programmes for professionals in the audiovisual industry. His research concerns methodologies, models and applications of informatics to the production processes of multimedia artifacts and the simulation of cognitive processes. His papers are published in international journals, books, conference proceedings. He carries on some production activity in multimedia communication, hosted by events at the international level.

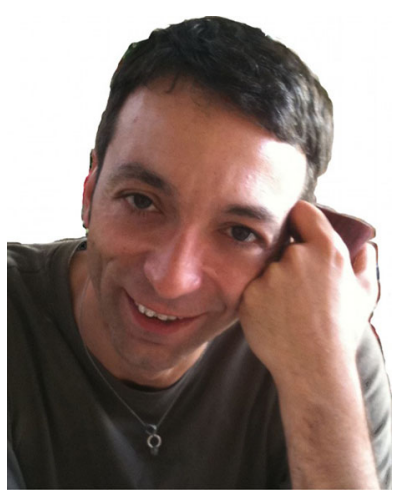

Antonio Pizzo $\mathrm{PhD}$, is Associate Professor at University of Turin where he teaches Theatre and Multimedia, and Dramaturgy. He is the founder and a project designer for www.officinesintetiche.it, where he has been collaborating with different artists (Marcel•lì Antunez Roca, Rosa Sanchez e Alein Baumann, Ali Zaidi, Antonella Usai, Andrea Valle, Alessandro Amaducci). In the last ten years his research has been focused on performance, drama and technology. He is one of the founder of CIRMA (Centro per la Ricerca sul Multimediale e l'Audiovisivo - www.cirma.unito.it) where he contributed to develop a computational model of drama (i.e. the Drammar Ontology) and a study on synthetic character as virtual museum guide (http://dramatour.di.unito.it). On this topic he wrote Teatro e mondo digitale (Venezia, Marsilio, 2003), and has published numerous paper in journals and proceedings in Multimedia, Virtual Storytelling, and Artificial Intelligence. Beside, grounded on his Phd dissertation on vernacular actors in Italy, he has develop a specific interest for the cultural implications of Neapolitan Theatre, publishing a number of papers and essays. His last book Scarpetta e Sciosciammocca. Nascita di un buffo (Roma, Bulzoni, 2009) is about the pivotal figure of Eduardo Scarpetta and the born of the comic character Don Felice Sciosciammocca. For a detailed list of publication see: www.cirma.unito.it/pizzo 